\title{
Self-sealing of cracks in concrete using superabsorbent polymers
}

\author{
H. X. D. Lee, H. S. Wong*, N. R. Buenfeld
}

Department of Civil and Environmental Engineering, Imperial College London, UK

\begin{abstract}
Cracks in concrete can self-heal when exposed to prolonged wetting, but this is limited to narrow cracks. In practice, cracks $>0.2 \mathrm{~mm}$ cause leakage and impair performance of structures. The potential of superabsorbent polymers (SAP) to self-seal such cracks was investigated via transport experiments, microscopy and modelling. Forty samples containing SAP and through-thickness cracks were subjected to $0.12 \mathrm{wt} . \% \mathrm{NaCl}$ at $4 \mathrm{~m} / \mathrm{m}$ pressure gradient to simulate groundwater seepage. Results show that SAP can reswell and seal cracks, for example in the case of $0.3 \mathrm{~mm}$ cracks reducing peak flow rate and total flow by $85 \%$ and 98\% respectively. Increasing SAP dosage accelerates sealing, but imparts a strength penalty and this limits practical applications. Modelling suggests that the effectiveness of SAP can be enhanced by increasing its re-swelling ratio and particle size, and depressing its initial swelling. These variables increase the SAP exposed in a crack and the gel volume available to seal it.

Keywords: Durability (C); Permeability (C); Transport properties (C); Admixture (D); Superabsorbent polymer

* Corresponding author: Tel.: +44(0)20 7594 5956, E-mail: hong.wong@imperial.ac.uk
\end{abstract}

\section{Introduction}

Concretes that are appropriately formulated and manufactured tend to be durable and have good resistance to water penetration. However, concrete is prone to cracking when exposed to structural loading or non-structural factors such as shrinkage, thermal effects and physiochemical reactions [1]. Indeed, a 
fundamental principle of structural design is that concrete is cracked in the tension zone. Cracking causes leakage and affects watertightness, a critical serviceability requirement for many structures such as basements, retaining walls, reservoirs, dams, tunnels, pipelines and waste repositories. Cracks also act as pathways for aggressive agents, thereby accelerating deterioration mechanisms [2]. When cracks percolate, their influence on transport fair outweighs that of capillary pores because of their larger size and shorter flow lengths. Therefore, cracks not only affect watertightness, but also long-term durability of concrete structures.

Cracks may heal when exposed to water [3-6,44], but this is usually limited to narrow cracks $(<0.3 \mathrm{~mm})$ and dependent on many conditions such as mix composition, hydraulic pressure and temperature. The crack width limit for self-healing have been reported in some studies as $0.05 \mathrm{~mm}$ or below $[6,26]$. According to current design guidance, concrete with cracks wider than $0.1 \mathrm{~mm}$ are expected to lose their watertight characteristics $[2,7,8]$. For example, ACI 224R-01 [7] recommends a crack width limit of $0.1 \mathrm{~mm}$ for waterretaining structures while Eurocode 2 [8] specifies that full thickness cracks should be less than $0.2 \mathrm{~mm}$ to limit leakage for structures exposed to an hydrostatic pressure gradient of $\leq 5$. Crack width can be limited by appropriate reinforcement detailing and provision of movement joints. However, special measures (e.g. external liners and pre-stressing) will be required if no leakage is permitted [8]. Methods such as surface coating, resin injection and integral water resisting admixtures are also often used to prevent leakage, but are not always effective, for example where there is significant movement, e.g. ground subsidence. Coatings deteriorate and require maintenance or reapplication. Water resisting admixtures are generally divided into hydrophobic or water-repellent chemicals, finely divided solids and crystalline materials. Finely divided solids and hydrophobic waterproofing admixtures are not considered effective in crack blocking. Some crystalline type admixture may seal very fine cracks, but only by reacting with unreacted cement and moisture to form crystalline products [9]. Many claims have been made concerning the effectiveness of these admixtures, but most reported tests focus on their effect on the reduction of permeability of un-cracked concrete. There seems to be a lack of independent data to substantiate their effect on crack blocking [10].

Advances in materials science have led to the development of a range of smart adaptive materials that heal themselves when cracks develop. A well-known example is a self-healing polymer containing 
embedded microcapsules filled with a healing agent that is ruptured during cracking, releasing the agent into the crack where it mixes with a catalyst and polymerises [11]. There have been other similar attempts to induce self-healing in concrete using brittle glass fibres or capsules containing adhesives [12, 13]. More recently, much emphasis has been placed on developing bacteria-induced precipitation to heal cracks e.g. the work of Van Tittelboom et al. [14] and Jonkers et al. [15]. For successful application in civil engineering structures, new materials need to satisfy many criteria including affordability, availability, robustness, durability, performance across a range of exposure environments, chemically inertness and low toxicology. Superabsorbent polymer (SAP) is a promising class of materials that potentially meets these criteria.

Superabsorbent polymers, also known as hydrogels, are cross-linked polymers that have the ability to absorb a disproportionately large amount of liquid, expanding to form an insoluble gel. A unique characteristic of SAP is that its swelling rate and capacity can be altered depending on the polymer type and properties of the liquid including composition, temperature and pressure. For example, the swelling ratio of SAP in deionised water can be greater than $500 \mathrm{~g} / \mathrm{g}$, but it drops to about $10-20 \mathrm{~g} / \mathrm{g}$ in typical concrete pore solution. The swollen gel forms a barrier to flow and it gradually releases absorbed water when the surrounding humidity drops. The main application of SAP is in personal hygiene products (diapers). Other uses include biomedical (bandages), pharmaceutical (drug delivery), agricultural (soil conditioning), waste solidification, meat packaging and water blocking tapes for undersea cables [16]. In concrete technology, research on SAP has mainly focused on its use as an internal curing agent to mitigate autogenous shrinkage in low w/c mixes $[17,18]$. Other proposed applications include rheology control, frost protection $[19,20]$ and crack sealing/healing [21-26]. A state-of-the-art report on the application of superabsorbent polymers in concrete has been published by RILEM [27].

The use of SAP as an admixture for self-sealing cracks in cement-based materials was described by Tsuji et al. [21, 22] and this concept was further explored by Lee et. al. [23, 24] and Snoeck et al. [25, 26]. In the work of Tsuji et al. [22], mortar specimens with w/c ratio 0.5 and sand/cement ratio 1.0 containing up to $3 \%$ vol. of SAP ( $5 \%$ wt. cement) were prepared and mechanically loaded to form a single $0.1 \mathrm{~mm}$ wide through crack. The flow rate of water through the crack was monitored for 3 hours. Their result showed that 
the initial flow rate for mortars containing SAP was $90 \%$ lower than that of the control sample and the flow rate rapidly decreased over the following 3 hours. Using neutron radiography to study water penetration, Snoeck et al. [25], found that mortars containing SAP had lower capillary absorption in comparison to the control sample. Snoeck et al. [26] also demonstrated the use of SAP to promote self-healing in microfibrereinforced mortars exposed to wet-dry cycles in water. They observed that cracks up to $0.13 \mathrm{~mm}$ in width healed completely by $\mathrm{CaCO}_{3}$ precipitation, which led to decrease in permeability and regain in mechanical properties.

The aim of this study is to investigate the feasibility of SAP as an admixture for self-sealing cracks in concrete. Our focus will be cracks wider than $0.1 \mathrm{~mm}$ because they have limited ability to self-heal naturally, cause leakage and impair the watertightness of concrete. Forty samples containing four types of SAP based on partially neutralised acrylates or acrylate/acrylamide copolymers at varying dosages were prepared. A single through-thickness crack of between 0.1 and $0.4 \mathrm{~mm}$ width was induced in each specimen, which was then subjected to a flow of $0.12 \mathrm{wt} . \% \mathrm{NaCl}$ at hydrostatic pressure gradient of $4 \mathrm{~m} / \mathrm{m}$ to simulate groundwater ingress. Flow was monitored continuously to study the effect of SAP type and dosage, and crack width on healing, and the results were compared against control samples that did not contain SAP. In addition, an analytical model was developed to predict the fraction of crack sealed as a function of crack width and SAP particle size, dosage and swelling characteristics. The model was applied to support experimental results and to provide further insights on factors influencing the efficiency of SAP for crack sealing.

\section{Crack sealing mechanism}

Fig. 1 illustrates the envisaged self-sealing mechanism. When concrete is batched, the mix water reaches a very high $\mathrm{pH}(\sim 12.5-13)$ and ionic concentration $(\sim 150-700 \mathrm{mmol} / \mathrm{L})$ within minutes in contact with cement because of rapid dissolution of the cement compounds releasing ions including $\mathrm{Ca}^{2+}, \mathrm{K}^{+}, \mathrm{Na}^{+}$, $\mathrm{OH}^{-}$and $\mathrm{SO}_{4}{ }^{2-}$ [28]. As such, SAP that is added during batching will initially swell at a much reduced 

capacity compared with SAP in freshwater. Calcium ions in the mix water forms a bidentate complex with the acrylates of the SAP [29], which further limits its swelling [30, 31]. The initial swelling is also confined by the mixing and compaction processes. As cement hydrates and concrete self-desiccates, the SAP gradually releases its absorbed water and shrinks, leaving behind voids of tens to hundreds of microns in size in the cement paste (Fig. 1a). These voids can be viewed as macro-defects, and so cracks that form during the service life of the concrete structure are likely to propagate through them (Fig. 1b). The SAP lies dormant in the microstructure until a crack occurs through the SAP voids, exposing the polymer to the external environment. When the concrete is then subjected to wetting, ingress of water triggers the SAP to swell again. External fluids such as precipitation and groundwater have much lower ionic concentration compared to concrete pore solution and so the re-swelling of SAP will increase significantly. The reduced physical confinement will also increase the re-swelling capacity of the SAP. The swollen SAP forms a soft gel that expands beyond the void and into the crack, subsequently slowing down or preventing further flow (Fig. 1c). In addition to the direct physical blocking effect of the swollen SAP, the reduced crack width and flow rate may promote autogenous healing of cracks [3-6]. If the concrete is exposed to wetting and drying cycles, then the delayed released of water by the SAP during drying periods may also assist self-healing. These effects would help retain the water-tightness of cracked structures. To the best of the authors' knowledge, the ideas presented here were first described in the paper Lee et al. [23].

\section{Experimental}

\subsection{Materials}

Two cements were used in this study: a) white Portland cement (CEM I, 52.5 N) and b) Portland composite cement containing 27\% fly ash (CEM II/B-V, 32.5R) complying with BS EN 197-1, from Lafarge. Their oxide compositions are shown in Table 1. The specific gravity of the CEM I and CEM II cements were 3.04 and 2.92 respectively. The aggregates used in mortar and concrete mixes were quartz sharp sand $(<5$ $\mathrm{mm})$ and Thames Valley gravel $(<10 \mathrm{~mm})$. Their particle size distribution, specific gravity and water 
absorption are shown in Table 2. The aggregates were oven-dried at $100^{\circ} \mathrm{C}$ for 24 hours and cooled to room temperature prior to use. Deionised water was used as batch water.

Twenty types of commercially available SAP were obtained, from which four were selected and used for this study. The rest were rejected mainly because it was deemed that their particle sizes and swelling properties were inappropriate for this application. The selected polymers were either polyacrylate or polyacrylate-co-acrylamide. The SAPs are the same polymers denoted as S1, S2, S3 and S5 in an earlier paper [23]. The SAPs are in a white powder form with particle size ranging from several micrometers up to $500 \mu \mathrm{m} . \mathrm{S} 3$ has the largest particle size, followed by S2, S5 and S1. When viewed using an optical microscope in transmitted light and scanning electron microscope, S1, S2 and S5 appear as smooth, angular shaped granules with a small amount of convoluted sheets. This is a result of the grinding process after solution polymerization in their manufacture. S3 has a very rough surface texture and appears to be agglomerates of smaller particles with high surface area due to the two-step suspension polymerization manufacturing process. S1 has the smallest particle size. Fig. 2 shows scanning electron micrographs highlighting the differences in particle size, surface texture and particle shape of the SAPs.

The properties of the SAPs including their swelling ratios in deionised water, $0.12 \mathrm{wt} . \% \mathrm{NaCl}$, synthetic shallow groundwater and synthetic pore solution are shown in Table 3 . The composition of synthetic groundwater was based on a relatively concentrated groundwater with ionic strength of $21 \mathrm{mmol} / \mathrm{L}$ [37], in $\mathrm{mmol} / \mathrm{L}: \mathrm{NaHCO}_{3}(8.2), \mathrm{CaSO}_{4}(1.04), \mathrm{MgSO}_{4}(2.08)$ and $\mathrm{CaCl}_{2}(0.14)$. The composition of synthetic pore solution was based on pore solution extracted from a $0.5 \mathrm{w} / \mathrm{c}$ ratio cement paste within 30 minutes of mixing [28], in mmol/L: $\mathrm{CaSO}_{4}(20.6), \mathrm{K}_{2} \mathrm{SO}_{4}(163.4), \mathrm{KOH}(71.2)$ and $\mathrm{NaOH}$ (73.9). Swelling ratio was measured using suction filtration. $100 \mathrm{mg}$ of SAP predried at $50^{\circ} \mathrm{C}$ was immersed in $50 \mathrm{~mL}$ of the solution for 60 min at $20^{\circ} \mathrm{C}$. The swollen SAP was then filtered by suction ( $\sim .17$ bar) over a pre-saturated filter paper for 5 min and weighed. The swelling ratio is calculated as the water uptake by mass of dry SAP. The obtained values are close to those reported in the literature $[17,18,26,32]$. 


\subsection{Samples}

Fifteen mixes consisting of neat cement paste, mortar and concrete were prepared. These are divided into four series and their details are shown in Table 4. Series I and II consist of cement pastes with a target free w/c ratio of 0.3 . Series III and IV consist of mortars (w/c 0.5$)$ and concretes (w/c 0.4$)$ respectively. Mortars were designed with $50 \%$ vol. sand, while the concretes were designed with $65 \%$ vol. aggregates at sand-total aggregate ratio of 0.35 . The SAP dosage $(\alpha)$ ranged from $0 \%$ to $13 \%$ by weight of cement. For Series II and IV, white Portland cement was used as the binder to reduce alkalinity and calcium nitrate tetrahydrate (analytical grade, Fluka) was added to increase the calcium content of the pore solution. The purpose of this was to depress the initial swelling of SAP $[33,34]$ so that a higher SAP dosage was possible. Furthermore, this increases the reswelling capacity of SAP so that the potential for crack sealing is improved. The amount of calcium nitrate tetrahydrate added was $4 \%$ by weight of cement.

Mix design was carried out by absolute volume. Water contents for the mortar and concrete mixes were corrected for aggregate absorption. Mixes with SAP contained additional batch water to account for the amount absorbed by the SAP so that the target free w/c ratio is achieved. This was determined by conducting many trial mixes to measure the additional water required to obtain a mix with similar consistency to the control mix. Consistency was judged by comparing the spread of the freshly prepared mix on a flow table. Swelling ratio of the SAP was then measured based on the difference in water content between the mix containing SAP and the control [35]. The results are shown in Table 4 and it can be seen that the swelling ratios measured in the fresh mix are close, but lower than the free swelling ratios measured in synthetic pore solution (Table 1), which is to be expected. The results also show the effect of calcium nitrate in depressing the swelling ratio. It should be noted here that the physical presence of swollen SAP may influence the rheology of the fresh mix [47] to the extent that it affects the accuracy of the estimated swelling ratios. Possibly, a more accurate method for measuring the actual swelling ratio in the cement paste is through detailed image analysis of BSE images, for example as described in Lee et al. [35] and Justs et al. [48].

Batching was done in a pan mixer. Cement, SAP and aggregates were mixed thoroughly for 2 minutes. Water was then added and mixed for another 3 minutes. In mixes marked with *, calcium nitrate was first 
dissolved in batch water before addition. Samples were then cast into cylindrical steel moulds $(100 \varnothing \times 150$ $\mathrm{mm}$ ) with specially fabricated trapezoid inserts to produce grooves on two opposing sides of the samples for inducing cracks, as shown in Fig. 3. The moulds were filled and compacted in three equal layers on a vibrating table. The compacted samples were then covered with plastic sheets and stored in a fog room at $100 \% \mathrm{RH}$ and ambient temperature $\left(21^{\circ} \mathrm{C}\right)$ for 5 days. The hardened samples were then demoulded and cured for another 9 days in the fog room. The top and bottom of each sample was ground to create a flat surface. The sample was then sealed cured by wrapping in a generous amount of cling film then placed in sealed polythene bags and stored at ambient temperature and humidity $\left(21^{\circ} \mathrm{C}, 55 \% \mathrm{RH}\right)$ for a further 2 weeks.

\subsection{Inducing crack}

A single through-thickness crack was induced at the centre of each sample by tensile splitting using the loading device shown in Fig. 3b. Pressure was applied through a metal bar placed at the tip of each side groove of the sample. The applied pressure was gradually increased until a single through crack was produced. This procedure was very effective because the shape of the sample lends itself to splitting between the grooves without producing visible broken pieces (Fig. 3c). The distance between the tip of each side groove i.e. the crack breadth was $30 \mathrm{~mm}$. The cracked sample was then briefly taken apart and reassembled to ensure that a complete through crack was produced. A silicone rubber seal attached to a thin stainless-steel plate was fitted into the side grooves of the sample. A set of Perspex strips were then inserted into the side grooves and the assembled sample was held together using three stainless-steel hose clamps (Fig. 3c). The width of the crack was adjusted by adjusting the Perspex inserts and clamps. Tightening the Perspex strips widens the crack, while tightening the hose clamps reduces crack width. A stereomicroscope and image analysis were used to measure the crack width on six locations on the top and bottom flat surfaces of each sample, and the results were averaged. An angled light source was used to enhance the contrast of the crack and to increase the accuracy of the crack width measurement. In total, forty samples with average crack widths ranging from $0.1 \mathrm{~mm}$ to $0.4 \mathrm{~mm}$ were prepared in this manner for testing. 


\subsection{Measuring flow through crack}

Fig. 4 shows the setup of the flow through crack (FTC) experiment, which was specifically designed to study transport of fluids in cracked concrete [36]. The ends of the sample were attached to an inlet and an outlet cell using silicone sealant. These cells were fitted with sensors to monitor the temperature of the inlet solution, and $\mathrm{pH}$ and resistivity of the outlet solution. The inlet cell was connected to a tank containing $0.02 \mathrm{M}(0.12 \mathrm{wt}$. \%) sodium chloride solution as the permeating medium, positioned to apply a constant 0.6 $\mathrm{m}$ head to the sample. This generates a hydraulic gradient of $4 \mathrm{~m} / \mathrm{m}$ to simulate groundwater seepage in basements. The flow through the cracked sample was measured every minute using a data logger. Flow was monitored until it became negligible. A note should be made concerning the choice for the test solution. Natural groundwater varies greatly in composition since it depends on factors such as aquifer type, mineral solubility, residence time and temperature. However, the principal ions are calcium, magnesium, sodium, potassium, sulphate, chloride and bicarbonate [37]. Because of the variability in groundwater composition, a $0.02 \mathrm{M} \mathrm{NaCl}$ solution was used as a simple substitute for groundwater. This selection was based on our measurements (Table 3) showing that the swelling ratios of the SAP in $0.02 \mathrm{M} \mathrm{NaCl}$ are very close to that in a relatively concentrated groundwater solution.

\subsection{Flow through crack containing deposited SAP}

SAP particles were deposited directly on the crack surface to examine if this will alter crack sealing compared to samples containing cast-in SAP. Replicate paste sample CP1 was prepared and split into two halves as described in Section 3.3. The edges of each halve were sealed with duct tape to create a barrier for ponding. Then, $50 \mathrm{ml}$ distilled water was poured on the crack surface and $25 \mathrm{mg}$ of SAP S1 were sprinkled and mixed into the pond. The sample was then dried at $50^{\circ} \mathrm{C}$ for 24 hours to allow the SAP to deposit on to the crack surface. The SAP concentration on the crack, i.e. the mass of dried SAP exposed per unit crack area is thus $0.52 \mathrm{mg} / \mathrm{cm}^{2}$, which is theoretically equivalent to that of samples containing $5 \%$ SAP by weight 
of cement at $\mathrm{w} / \mathrm{c}$ ratio of 0.3 . The two halves were then reassembled with the rubber seals, Perspex inserts and clamps, and tested as described in Section 3.3. The sample was labelled as CP1-5S1-dep.

\subsection{Microscopy}

At the end of the FTC experiment, samples were examined and imaged with a stereomicroscope to observe the extent of the crack sealing. The effect of SAP on the microstructure was also examined using backscattered electron microscopy. The samples were oven-dried at $50^{\circ} \mathrm{C}$, trimmed into $40 \times 20 \times 10 \mathrm{~mm}$ blocks, and vacuum impregnated with a low viscosity fluorescent epoxy resin according to the procedure described in [38]. The sample surface was then ground using silicon carbide papers of grit sizes 220,500 and 1200, and diamond polished at $9,6,3,1$ and $1 / 4 \mu \mathrm{m}$. The polished surface was then carbon coated and examined with a field-emission scanning electron microscope at $10 \mathrm{keV}$ beam energy.

\section{4. $\quad$ Results}

\subsection{Flow-through crack and crack sealing}

\subsubsection{General observations}

The measured flow rate and cumulative flow over time for all samples are plotted in Figs. 5 to 10. These are grouped according to sample series and average crack width. The results show that flow rate increased rapidly and reached a peak value within the first five minutes of measurement. Subsequently, the flow rate remained relatively constant for a period of time, and then gradually declined to a negligible value. This seems to be the characteristic of most samples, with or without SAP. The drop in flow rate is due to either autogenous crack healing or self-sealing from the action of the swollen SAP. The cumulative flow also showed a relatively consistent trend. Total flow increased rapidly at early stages of the experiment and then gradually stabilised after the first 24 hours of measurement. Of the forty sets of measurements, four had to be terminated before complete sealing occurred because the total flow exceeded the $100 \mathrm{~L}$ capacity of the test 
setup. These were the CP1 samples with $0.37 \mathrm{~mm}$ crack width (Fig. 8) and the control sample CP2 with 0.3 mm crack width (Fig. 7). For samples containing SAP, all but one gave much lower cumulative flow relative to the control sample. The exception was CP1-5S1 (Fig. 5b). Overall, the addition of SAP decreased peak flow rate and cumulative flow by up to $85 \%$ and $98 \%$ respectively, and sealed the $0.3 \mathrm{~mm}$ crack.

\subsubsection{Effect of SAP type}

Fig. 5 presents the results from Series I, which are pastes containing 4-5\% SAP tested at an average crack width of $0.2 \mathrm{~mm}$. Samples containing S2 (CP1-5S2) and S5 (CP1-4S5) showed significantly lower peak flow rates and cumulative flow relative to the control. For CP1-5S2, the reduction was $55 \%$ and $80 \%$ for peak flow rate and cumulative flow respectively. For CP1-4S5, tests were carried out on two replicate samples and the results show a consistent reduction in peak flow rate by $75-85 \%$, and reduction in cumulative flow by $75-80 \%$ compared to the control. Samples containing S3 (CP1-5S3) gave a slightly higher peak flow rate, but the total flow was $25 \%$ lower than the control. However, the total flow for samples containing S1 (CP1-5S1) was $80 \%$ higher than the control. These results suggest that S2 and S5 are more effective than S1 and S3 for sealing cracks. Therefore, a greater emphasis was placed on the use of S2 and S5 in subsequent experiments.

\subsubsection{Effect of calcium nitrate and SAP dosage}

As stated in Section 3.2, selected mixes contained dissolved calcium nitrate to depress the initial swelling of the SAP. The purpose of this was to enable higher dosages of SAP in the mix, to increase the reswelling capacity of the SAP and thereby its potential for crack sealing. With this approach, we were able to cast samples with up to $13 \%$ SAP by weight of cement. The FTC data for samples containing $13 \%$ S2 and $8 \%$ S5 are plotted in Fig. 6. Compared to the data from Series I (Fig. 5), the results show the higher SAP dosage produced a more rapid crack sealing and lower cumulative flow. The total flow at the end of the experiment for CP2-13S2* and CP2-8S5* was only around $0.6 \mathrm{~L}$ compared to $6.2 \mathrm{~L}$ for $\mathrm{CP} 2 *$ (90\% reduction) and 27.3 L for the control CP2 (98\% reduction). This is clearly a result of the greater amount of SAP that is exposed by the crack. It should be clarified here that this is not due to densification of the pore structure from internal 
curing because flow occurs via the induced crack, rather than the pore structure of the sample. It is also interesting to note that the addition of calcium nitrate decreased the flow rate and cumulative flow of the control sample. This can be seen by comparing the data from $\mathrm{CP} 2 *$ to that of $\mathrm{CP} 2$ in Fig. 6 . A possible explanation for this is that the higher calcium concentration in CP2* led to a more rapid autogenous crack healing resulting from more precipitation of calcium carbonate and possibly calcium hydroxide. To the best of our knowledge, this enhanced self-healing brought by calcium nitrate has not been reported before.

\subsubsection{Effect of crack width}

In the next set of experiments, replicate samples from Series II were subjected to a larger crack width of $0.3 \mathrm{~mm}$ and put through the FTC test. Comparing the results in Fig 7 to Fig 6 shows that the flow rates and cumulative flow for all samples increased significantly with increase in crack width, which is to be expected. Nevertheless, crack sealing with SAP remained effective. The flow rates for CP2-8S5* and CP2-13S2* reduced to negligible values after 200 minutes. In contrast, the flow rate for CP2 remained very high at about $2500 \mathrm{~mm}^{3} / \mathrm{s}$ throughout the experiment. Unfortunately, the measurement for CP2 had to be stopped after 700 minutes when its total flow exceeded the $100 \mathrm{~L}$ capacity of the test setup. Judging from the trend of the collected data, the final cumulative flow for CP 2 would have exceeded $100 \mathrm{~L}$ by several times. In contrast, the final cumulative flow for $\mathrm{CP} 2-8 \mathrm{~S} 5 *$ and $\mathrm{CP} 2-13 \mathrm{~S} 2 *$ were only $4.9 \mathrm{~L}$ and $2.3 \mathrm{~L}$ respectively, a reduction of at least $95 \%$ and $98 \%$. The results also show that the presence of SAP was able to decrease flow rate and total flow beyond the levels achieved by adding calcium nitrate alone $\left(\mathrm{CP} 2^{*}\right)$. These results demonstrate the effectiveness of the combined action of calcium nitrate and SAP in sealing cracks.

In another set of experiments, replicate samples from Series I and Series II were subjected to crack widths ranging from 0.1-0.4 mm. Fig. 8 shows the measured peak flow rate against crack width and the results are compared against the Hagen-Poiseuille equation for steady-state laminar flow between parallel plates, given by $Q=b w^{3} \Delta P / 12 \mu L$, where $Q, b, w, \Delta P$, $\mu$, and $L$ are the flow rate, crack breadth, crack width, differential pressure, fluid viscosity and length of the flow path. Data from samples with SAP deposited directly onto the crack surface (CP1-5S1-dep) are also plotted on Fig. 8. The results show that the measured flow rates increased significantly with crack width and follow approximately the trend of the Hagen- 
Poiseuille equation. However, the measured flow rates are significantly lower than theoretical values. This is expected because the actual geometry, tortuosity and surface roughness of real cracks have a major influence on flow, but these are not captured in the Poiseuille equation. Flow rates for the control, sample with cast-in SAP and sample with deposited SAP are lower than the theoretical values by an average of $47 \%, 70 \%$ and $95 \%$ respectively. Overall, the results show that SAP is effective in decreasing peak flow rates for a range of crack widths. It is also evident that a greater reduction in peak flow rate was achieved when SAP was deposited onto the crack compared to cast-in SAP. A possible explanation is that the SAP deposited on the crack surface has not been mixed with the pore solution and is not physically confined by the SAP void along the crack surface.

\subsubsection{Crack sealing in mortars and concretes}

Results from mortars (Series III) and concretes (Series IV) are presented in Fig. 9 and 10 respectively. For both sets of results, the FTC experiment was carried out on samples with $0.3 \mathrm{~mm}$ average crack width. Similar to paste samples, the mortars and concretes containing SAP showed more rapid crack sealing and significantly lower flow rates and cumulative flow relative to the control. The mortars (M-5S1 \& M-5S2) gave $25-50 \%$ lower peak flow rates and $80-88 \%$ lower cumulative flow compared to the control. S2 was more effective than S1, consistent with results from Series I. The concretes (C-13S2* \& C-8S5*) gave very similar peak flow rates to the control, but they dropped rapidly to negligible values after 13 hours of measurement compared to 134 hours for the control. Consequently, the total flow through C-13S2* \& C$8 \mathrm{~S} 5 *$ are less than $5 \%$ of the control.

\subsubsection{Effect of SAP dosage on cumulative flow and time to crack sealing}

Fig. 11 shows the effect of SAP dosage on the time to reach a negligible flow rate and on the cumulative flow. The results are compiled from data taken on all samples from Series I-IV with crack widths of $0.2 \mathrm{~mm}$ and $0.3 \mathrm{~mm}$. A 'negligible' flow rate is arbitrarily defined here as $10 \mathrm{~mm}^{3} / \mathrm{s}\left(=0.33 \mathrm{~mm}^{3} / \mathrm{s} \mathrm{per} \mathrm{mm} \mathrm{crack}\right.$ breadth). Please note the logarithmic scale on the Y-axis. The time to crack sealing ranged from 1 hour to about 5 days. Overall, the figure shows that increasing SAP dosage has a huge effect on accelerating crack 
sealing and decreasing the total flow through the crack. A difference of more than a factor of 10 can be observed. The figure also suggests that reductions in time to crack sealing and cumulative flow were insignificant when the SAP dosage was above $8 \%$ (for crack widths of $0.2-0.3 \mathrm{~mm}$ ).

\subsection{Visual assessment of crack sealing}

Samples were examined with a stereomicroscope immediately after the FTC experiment. Typical images of the upstream and downstream faces of a sample containing SAP are shown in Fig. 12. The upstream face was in constant contact with the test solution, so it can be seen that the swollen SAP forms a transparent gel that fills a significant portion of the crack (Fig. 12a). In contrast, the downstream face is dry because flow has stopped by the end of the FTC experiment due to crack sealing. Therefore, the SAP particles near the downstream face are not swollen and the crack is clearly visible (Fig 12c). The upstream face was observed again after the sample was dried at room temperature for 24 hours. It can be seen that the swollen SAP has shrunk and the crack is clearly visible again (Fig. 12b). Figs. 12d \& 12e show area matching views of the internal crack surface before and after wetting with the test solution. Remnants of the dry SAP can be seen residing in their voids. When wetted, the SAP swells beyond its original void and expand into the crack space. These observations correspond well with the FTC results and support the envisaged crack sealing mechanism described in Section 2 and Fig. 1. It is also worth noting that no significant deposits were observed on the sealed cracks, indicating that the crack is not blocked when the sample is dry.

\subsection{Microstructure of samples containing SAP}

Fig. 13 shows a selection of micrographs from BSE imaging to highlight the size, shape and distribution of the SAP particles and voids, and their effect on the microstructure of cement-based materials. It can be seen that the SAP voids are isolated and well-distributed in the paste. Their size ranges from $\sim 10 \mu \mathrm{m}$ to over 
$500 \mu \mathrm{m}$, depending on the initial size of the dry SAP and the amount of swelling in the paste. These can be easily differentiated from entrapped air voids, which are spherical and empty. The boundary of the SAP void tends to follow the shape of the collapsed SAP particle, which may appear as solid, porous, cellular or narrow ring-shaped particle. The appearance of the SAP depends on the original particle shape, how it is sectioned during sample preparation for microscopy, and the way in which it is restrained by the surrounding cement paste when it dries.

Samples containing S1, S2 and S5 tend to show a gap between the SAP and cement paste due to shrinkage of the polymer (Fig. 13 a, c, d). However, this feature is not seen in samples containing S3 (Fig. 13b). This suggests that the rough texture and large surface area of S3 helps to strengthen its adhesion with the cement paste (Fig. 2c). Occasionally, the SAP voids appear to contain small cement grains that have subsequently reacted to form hydration products within the water reservoirs of S3. The strong bond between S3 and cement paste will interfere with its re-swelling capacity, and this would affect its ability to seal cracks as observed in the FTC results shown in Fig. 5.

The cement paste surrounding SAP exhibits a highly variable microstructure, reminiscent of the aggregate-paste "interfacial-transition zone" and air void-paste interface [39-41]. It contains less cement particles compared to the bulk paste region farther away due to the disrupted packing of the cement grains. It also tends to be very porous and occasionally contains large calcium hydroxide deposits. These features can be attributed to the high water content on the surface of swollen SAP or possibly the early release of absorbed water into the surrounding paste. Shrinkage of the SAP when it dries may also lead to cracking of the surrounding cement paste. Samples from Series II and IV that contain high SAP dosages show very closely spaced SAP voids (Fig. 13c). The ratio of SAP void area to SAP particle is also smaller because of the depressed swelling as a result of the calcium nitrate addition. In mortars and concrete samples, it can be seen that the SAP voids are of the size of sand grains and they can span between aggregate particles. 


\subsection{Effect of high SAP dosage on compressive strength}

It is fairly well-established that the use of SAP often results in a decrease in compressive strength, even at low SAP dosages of less than $1 \%$ by mass of cement, see for examples Kovler [49] and Hasholt et al. [50]. To examine the effect of the relatively high SAP dosages used in this study on compressive strength, selected mixes of cement paste, mortar and concrete with and without SAP were prepared and $100 \mathrm{~mm}$ cube samples were cast in three replicates following the procedure described in Section 3.2. The cubes were demoulded after one day and then cured in water at $20^{\circ} \mathrm{C}$ for 28 days prior to compressive strength testing. The emphasis was on polymer S2 since this particular SAP was found to very effective for crack sealing.

The results of the 28-day compressive strength testing are shown in Table 5. For the control samples, it can be seen that increasing w/c ratio decreases strength. As expected, all specimens containing SAP achieved compressive strengths much lower than their respective controls. The level of strength reduction for the samples tested ranged between $80 \%$ and $87 \%$. This is due to the high volume of SAP voids in the microstructure as can be seen in Fig. 13. An interesting observation is that the strength of mixes containing $13 \%$ SAP was not significantly lower compared to that of mixes containing 5\% SAP. In fact, the amount of strength loss per $1 \%$ added SAP decreased from $\sim 17 \%$ (for $5 \% \mathrm{~S} 2$ ) to $\sim 7 \%$ (for $13 \% \mathrm{~S} 2$ ). This is due to the effect of the added calcium nitrate which decreases the swelling of the SAP and thus controls the volume of SAP voids in the mix containing 13\% SAP. Therefore, depressing the initial swelling of SAP helps to reduce its detrimental effect on strength.

\section{Modelling}

In this section, a mathematical model is developed and applied to better understand the factors influencing crack sealing with SAP. Here, we attempt to estimate the volume fraction of crack filled $(\psi)$ as a function of its width $(w)$, dry SAP particle size $\left(d_{o}\right)$, SAP dosage ( $\alpha$, mass fraction of cement), initial swelling ratio in cement paste $\left(S_{1}\right)$ and the subsequent re-swelling ratio $\left(S_{2}\right)$ triggered by ingress of external fluids via the crack. This will be achieved by first estimating the mass of SAP exposed in a crack, and then 
$d_{1}=d_{o}\left(S_{1} \frac{\rho_{S A P}}{\rho_{a b s}}+1\right)^{\frac{1}{3}}$

412 Where $\rho_{S A P}$ and $\rho_{a b s}$ are the densities of the dry SAP and absorbed solution respectively. Substituting (2) and 413 the above expressions into Eq. (1) leads to the following equation:

$m_{A}=\alpha C d_{o}\left(S_{1} \frac{\rho_{S A P}}{\rho_{a b s}}+1\right)^{\frac{1}{3}}$

414 When external fluids percolate through the crack, the SAP will absorb an amount equal to $S_{2} m_{A}$, causing 415 each SAP particle to swell beyond its void and into the crack. The volume fraction of crack filled $\psi$ is given 416 by:

$$
\psi=\frac{\text { Swollen SAP vol. }- \text { SAP void vol. }}{\text { Crack vol. }}=\frac{m_{A}\left(\frac{1}{\rho_{S A P}}+\frac{S_{2}}{\rho_{a b s}}\right)-m_{A}\left(\frac{1}{\rho_{S A P}}+\frac{S_{1}}{\rho_{a b s}}\right)}{w}=\frac{m_{A}\left(S_{2}-S_{1}\right)}{w \rho_{a b s}}
$$


Inserting Eq. (3) into Eq. (4) and rearranging gives:

$$
\psi=\frac{\alpha C d_{o}\left(S_{2}-S_{1}\right)}{w \rho_{a b s}}\left(S_{1} \frac{\rho_{S A P}}{\rho_{a b s}}+1\right)^{\frac{1}{3}}
$$

Fig. 14a shows the results of the fraction of crack filled as a function of crack width (w) for various dosages of SAP ( $\alpha$, wt. $\%$ of cement). The simulations were carried out on a sample with $0.3 \mathrm{w} / \mathrm{c}$ ratio, assuming that $S_{1}=10 \mathrm{~g} / \mathrm{g}, S_{2}=75 \mathrm{~g} / \mathrm{g}$ and $d_{o}=100 \mu \mathrm{m}$. The value for $S_{l}$ was chosen based on the measured swelling ratio in cement paste (Table 4), while the value for $S_{2}$ was chosen based on the free swelling ratio measured in 0.12 wt. \% $\mathrm{NaCl}$ solution (Table 3), which is the solution used in the FTC experiments. The densities of the dry SAP $\left(\rho_{S A P}\right)$ and absorbed solution $\left(\rho_{S A P}\right)$ were taken as $1660 \mathrm{~kg} / \mathrm{m}^{3}[16]$ and $1000 \mathrm{~kg} / \mathrm{m}^{3}$ respectively. The results show that the fraction of crack filled increased with increase in SAP dosage with decrease in crack width, as expected. The simulations also show that an SAP dosage of $1 \%$ by weight of cement would fully seal a crack of $0.2 \mathrm{~mm}$ and that a dosage of $5 \%$ by weight of cement would seal a crack of $0.7 \mathrm{~mm}$.

Further simulations were carried out to establish the main factors that influence crack filling and explore methods to enhance the effectiveness of SAP. A selection of the additional simulations is shown in Figs. 14b, $14 \mathrm{c}$ and $14 \mathrm{~d}$. The sensitivity analysis shows that the crack filling performance can be enhanced greatly by increasing swelling ratio $S_{2}$. For example, Fig. $14 \mathrm{c}$ shows that when $S_{2}$ is doubled to $150 \mathrm{~g} / \mathrm{g}$ from $75 \mathrm{~g} / \mathrm{g}$, the crack width filled by an SAP dosage of $1 \%$ increases to $0.5 \mathrm{~mm}$. This is because of the increased gel volume available to fill the crack. A similar effect can be achieved by doubling the SAP particle size $d_{o}$ from $100 \mu \mathrm{m}$ to $200 \mu \mathrm{m}$ (Fig. 14d) while maintaining the dosage. This is because a larger particle size increases the mass of SAP exposed in a crack as shown in Eq. 3. In practice, a larger SAP size would also increase the size of the swollen gel and therefore its ability to bridge cracks. In our experiments, polymer S1 has the smallest particle size (Fig, 2) and was the least effective in terms of crack sealing. This observation seems consistent with the model. Limiting the initial swelling $S_{I}$ is also beneficial. For example, Fig. 14b shows improved crack sealing performance when the initial swelling $S_{l}$ is reduced from $10 \mathrm{~g} / \mathrm{g}$ to $5 \mathrm{~g} / \mathrm{g}$. However, the improvement is small relative to that achieved by changing $S_{2}$ or $d_{o}$. This is because of opposing effects 
when $S_{l}$ is depressed. On the one hand, it increases the contrast $\left(S_{2}-S_{l}\right)$ and this improves crack sealing. On the other hand, it decreases the size of the SAP void and therefore lowers the probability of the SAP particles being intersected by a random crack.

\section{Discussion}

The reduction of flow with time in cracked concrete, i.e. autogenous healing, occurs as a result of several physical and chemical processes. For example, the crack could be blocked by loose fine particles dislodged from the fractured surface. A major contributing factor is that material upstream are weakened and eroded by leaching, and then carried by the percolating water and deposited in constrictions further downstream [36]. Other possibly contributing processes include swelling of the cement paste, carbonation of hydration products forming $\mathrm{CaCO}_{3}$ precipitates, dissolution and re-precipitation of calcium hydroxide within the crack, and hydration of exposed unreacted cement particles forming new products that fill the crack $[3,4$, 44]. In samples containing SAP, the swollen SAP forms a soft gel that expands into the crack. This "gel blocking" effect further reduces the rate and total flow, and the time to reach negligible flow compared to the control as seen in the FTC experiments. The swollen SAP is also expected to enhance autogenous healing by narrowing the crack pathway and physically trapping fine particulates or by acting as nucleation sites to encourage precipitation of solid products. However, the significance of this is unclear and further study is required. It is worth noting that no significant amounts of deposits were seen in the healed cracks, suggesting that healing is primarily due to physical blocking by swollen SAP. This is in contrast to the work of Snoeck et al. [26] who observed healed cracks were filled with $\mathrm{CaCO}_{3}$ deposits for samples that were continuously submerged or exposed to wetting and drying. The difference is probably due to the fact that our samples contained wider cracks and were not exposed to wet/dry cycles which facilitate carbonation and precipitation.

It is interesting to note that swelling of unconfined SAP in solution occurs instantaneously. However, when cast in concrete, the re-swelling of SAP exposed in a crack seems to occur at a much slower rate. This can be deduced from the observation that flow does not stop abruptly during the FTC experiments. Instead, it 
declines gradually, even in samples where the SAP dosage is estimated to be way above the amount required to completely fill the crack (Fig. 14a). In contrast, crack filling and the decrease in flow rate occurs very rapidly if SAP is deposited on the crack surface (Section 3.5) or placed in a model crack made of two parallel glass slides as shown in an earlier study [23]. There are several possible reasons for this. One is that the reswelling of cast-in SAP is much smaller than expected from the free swelling measured in solution. This may be due to the fact that the composition of fluid percolating the crack is not constant, but increases as a result of leaching of dissolvable species from the cement paste. This would also depend on the flow rate and residence time. Swelling may also be reduced because of confinement, either by the local geometry of the SAP void and crack, or by the bond between SAP and cement paste resulting from the rough surface texture of the polymer and growth of hydration products into the SAP void (as seen for S3, Fig. 13b).

Another reason for the delayed crack sealing is because calcium ions form a bidentate complex with the acrylates of the SAP that limits its initial swelling [29-31] when SAP is cast in concrete. However, monovalent cations (e.g. $\mathrm{Na}^{+}$) that are present in the fluid percolating the crack will gradually displace the $\mathrm{Ca}^{2+}$ complexes from the acrylate chain, and this leads to a recovery in swelling and improved absorption capacity. In another study, we investigated the swelling of SAP that was initially immersed in a calcium bearing solution, dried and then exposed to several cycles of $\mathrm{NaCl}$ solution [45]. It was observed that the swelling in $\mathrm{NaCl}$ was initially depressed, but gradually increases with repeated exposure to $\mathrm{NaCl}$. Certain types of SAP recover much faster and are able to achieve a complete recovery of the swelling. This shows that much of the restraint on swelling caused by the complexes can be removed when enough monovalent ions are available to displace $\mathrm{Ca}^{2+}$ from the acrylate chains.

The model developed in this study provides a useful tool for predicting crack-sealing with SAP and understanding factors that influence it. However, several simplifying assumptions were made in its development. For example, SAP particles were assumed to be mono-sized spherical particles and the crack was approximated as a flat plane of equal width through the cement paste. An actual crack may propagate through aggregate particles or around them, depending on the relative stiffness and strength of the aggregate, cement paste and the interface between them. If the crack propagates through aggregate particles, then the 
number of exposed SAP would be smaller than predicted. In reality, cracks are more likely to propagate through the SAP voids since they are a weak phase in the composite. Therefore, the number of SAP exposed in a real crack would be higher than that assumed in the model. Another assumption is that the crack needs to be completely filled with swollen SAP to stop flow, but this may not be necessary. As seen in Section 4.2 and Fig. 12, swelling of the SAP near the upstream wetting face is sufficient to seal the crack and stop flow. It is also not certain what the re-swelling ratio of the SAP is in a real crack, this was assumed to be equal to the free swelling value measured in solution. It would be interesting to carry out further tests to examine these assumptions.

At present, the relatively high dosage of SAP required for crack sealing will probably limit its practical application due to cost implications and the undesirable effect on strength. However, the SAP types used in this study are by no means ideal for the purpose of crack sealing. For example, spherical SAP could help reduce its adverse effects on strength [18]. There is much scope for optimisation since the physical and chemical properties of SAP can be tailored to influence swelling behaviour. For example, the degree of cross-linking and its distribution in the polymer can be altered to decrease constraint and elasticity, thereby increasing swelling and to produce a more deformable gel that fills cracks more effectively.

Modeling suggests that increasing the swelling contrast $S_{2}-S_{1}$ and increasing the particle size of SAP will enhance its performance for crack sealing. These effectively increase the amount of SAP exposed in a crack and the available gel volume to block the crack. Limiting the initial swelling $S_{l}$ would also be good from the point of view of reducing total porosity and therefore the effect of SAP on strength. This was observed in the strength results presented in Section 4.4 for mixes containing calcium nitrate, which was added to depress the initial swelling of the SAP. The model also suggests that cracks much larger than $0.4 \mathrm{~mm}$ can be selfsealed with SAP, assuming that the re-swelling of SAP in the crack is similar to the unconfined swelling in solution. Therefore, it would be interesting to test samples with crack widths wider than $0.4 \mathrm{~mm}$ in future. If true, then this would have the potential of reducing the stringent crack width requirement for water-retaining concrete structures, leading to thinner sections or less steel reinforcement. Stopping flow through large cracks would enhance overall durability in particular delaying the onset of reinforcement corrosion. 
More studies are required to examine the longevity of the crack sealing, its effectiveness in real exposure environments and the influence of SAP on properties of concrete, most notably mechanical properties and long-term durability. Studies have shown that the swelling of SAP remains fairly consistent when exposed to wetting and drying cycles [23]. This indicates that SAP can re-swell after drying with no apparent deterioration in swelling capacity, which is obviously desirable for crack sealing application. Another attraction of SAP is that the swollen gel is non-rigid and so it should potentially accommodate some crack movements, which would otherwise re-open cracks and disrupt autogenous healing based on solid precipitation. Whether or not SAP remains effective for sealing cracks subjected to higher hydraulic gradients or other types of percolating fluids remains to be seen. A high percolating fluid pressure may decrease the effectiveness of the SAP swelling and crack sealing, or wash out the exposed SAP. Another concern is that repeated swelling of SAP in concrete subjected to wetting and drying may have damaging effects to the SAP. Also, in saturated concrete exposed to a cold environment, the freezing of wet SAP may cause problems. It would also be interesting to carry out tests on mixes containing lower SAP dosages and with addition of calcium nitrate (to depress initial swelling). This is to establish if crack sealing remains effective at lower SAP dosages and to what extent the reduced initial swelling can help to limit strength loss. All of these issues merit further investigation.

\section{Conclusions}

The feasibility of superabsorbent polymers (SAP) as admixtures to impart the ability to self-seal cracks in concrete was demonstrated via a series of mass transport experiments, microscopy and modelling. Cement paste, mortar and concrete samples containing four SAP types at varying dosages and through-thickness crack widths between 0.1 and $0.4 \mathrm{~mm}$ were tested. The flow rate and cumulative flow of $0.12 \mathrm{wt} . \% \mathrm{NaCl}$ were measured over time to simulate groundwater seepage in basements. The main conclusions are:

a) SAP is effective in enhancing crack sealing. The peak flow rate and cumulative flow through samples containing cast-in SAP decreased by up to $85 \%$ and $98 \%$ respectively, relative to control samples with 
similar crack widths. This lead to the sealing of a $0.3 \mathrm{~mm}$ crack. Further research is required to verify its viability for sealing wider cracks.

b) Time to reach negligible flow $\left(<0.33 \mathrm{~mm}^{3} / \mathrm{s}\right.$ per mm crack breadth) ranged from 1 hour for samples containing SAP to about 5 days for the control samples. Increasing the SAP dosage accelerates sealing and decreases total flow through the crack significantly. Improvements of more than a factor of ten were observed.

c) Addition of calcium nitrate depresses the initial swelling $\left(S_{l}\right)$ of SAP. This is beneficial as it allows a higher SAP dosage, increases the swelling contrast $\left(S_{2}-S_{I}\right)$ and decreases the size of SAP voids in cement paste, therefore reducing its impact on strength. Calcium nitrate also enhanced autogenous healing of the control samples.

d) Microscopic examination following the end of flow through crack experiments revealed that SAP particles near the downstream face are dry while those near the upstream face swell to form a soft gel that fills the SAP void and crack. This is in agreement with the proposed crack sealing mechanism.

e) BSE imaging shows the SAP particles and voids $(\sim 10-500 \mu \mathrm{m})$ are well-distributed in the cement paste. The paste surrounding SAP resembles that of the aggregate-paste 'interfacial transition zone' in that it is highly variable, contains less cement and higher porosity compared to the bulk paste. It also contains large calcium hydroxide deposits. These features are due to the disrupted particle packing, high water content on the surface of SAP and possibly the early release of absorbed water into the surrounding paste. SAP with rough surface texture bonds very well with cement paste, which interferes with its reswelling capacity and ability to seal cracks.

f) At present, the relatively high dosage of SAP used in this study will limit practical applications due to the high costs involved and the undesirable effect on strength. For example, the addition of $5-13 \%$ SAP by weight of cement was found to reduce compressive strength by $80-87 \%$. Further work is necessary to establish the feasibility of crack sealing at lower SAP dosages and to develop means to limit strength loss, for example by depressing initial swelling via the addition of calcium-based salts. 
g) Analytical modelling shows that the effectiveness of SAP for crack filling can be enhanced by increasing the re-swelling ratio $\left(S_{2}\right)$ and dry particle size $\left(d_{o}\right)$, and depressing the initial swelling ratio $\left(S_{l}\right)$. These effectively increase the amount of SAP exposed in a crack and the gel volume that fills the crack. Simulations based on properties of the SAP used in this study show that an SAP dosage of $1 \%$ by weight of cement would seal a $0.2 \mathrm{~mm}$ crack, and an SAP dosage of $5 \%$ would seal a $0.7 \mathrm{~mm}$ crack, assuming the swelling of SAP in a crack is similar to unconfined swelling in synthetic solutions.

\section{Acknowledgement}

We would like to thank Andrew Morris for his assistance with sample preparation and BASF, Evonik and ETi for provision of SAP samples. This project was supported by an EPSRC Doctoral Training Award held by H.X.D. Lee.

\section{References:}

[1] Concrete Society (2010), Technical Report 22: Non-structural cracks in concrete, $4^{\text {th }}$ Edition, Camberley.

[2] Concrete Society (1995), Technical Report 44: The relevance of cracking in concrete corrosion of reinforcement, Camberley.

[3] C. A. Clear (1985), The effect of autogenous healing upon leakage of water through cracks in concrete, Cement and Concrete Association, Technical Report 559, Wexham Springs, Slough, UK

[4] N. Hearn (1998), Self-sealing, autogenous healing and continued hydration: What is the difference? Mater. Struct., 31, 8, 563-567.

[5] C. Edvardsen (1999), Water permeability and autogenous healing of cracks in concrete, ACI Mater. J., $96,4,448-454$

[6] Y. Yang. M.D. Lepech, E-H. Yang, V.C. Li (2009), Autogenous healing of engineered cementitious composites under wet-dry cycles, Cem Concr Res, 39, 382-390 
592 [7] ACI 224R-01 (2001), Control of cracking in concrete structures, American Concrete Institute, Detroit.

593 [8] EN 1992-3:2006, Eurocode 2: Design of concrete structures. Part 3: Liquid retaining and containing 594 structures, European Committee for Standardisation, Brussels.

595 [9] ACI 212.3R-10 (2010), Report on Chemical Admixtures for Concrete, American Concrete Institute, 596 Detroit, $46-50$

597 [10] Concrete Society (2013), The influence of integral water-resisting admixtures on the durability of $598 \quad$ concrete, CS 174, Camberley.

599 [11] S. R. White, N. R. Sottos, P. H. Geubelle, J. S. Moore, M. R. Kessler, S. R. Sriram, E. N. Brown, S. 600 Viswanathan (2001), Autonomic healing of polymer composites, Nature, 409, 6822, 794-797

601 [12] V.C. Li, Y.M. Lim, Y.W. Chan, (1998), Feasibility study of a passive smart self-healing cementitious 602 603 604 605 606 composite, Compos. Part-B Eng., 29, 6, 819-827

[13] C. M. Dry, (2000), Three designs for the internal release of sealants, adhesives, and waterproofing chemicals into concrete to reduce permeability, Cem. Concr. Res., 30, 12, 1969-1977

[14] K. Van Tittelboom, N. De Belie, D. Muynck, W. Verstraete (2010), Use of bacterial to repair cracks in concrete, Cem. Concr. Res., 40, 1, 157-166.

[15] H.M. Jonkers, A. Thijssen, G. Muyzer, O. Copuroglu, E. Schlangen (2010), Application of bacteria as 608 609

[17] O.M. Jensen, P.F. Hansen (2001), Water-entrained cement-based materials I. Principles and theoretical background. Cem Concr Res , 31 (4), 647-654.

[18] O.M. Jensen, P.F. Hansen (2002), Water-entrained cement-based materials II. Experimental observations. Cem Concr Res, 32 (6), 973-978.

[19] S. Mőnnig, P. Lura (2007), Superabsorbent polymers - An additive to increase freeze-thaw resistance of high strength concrete, Adv Const Mater Part V, 351-358 
616 [20] S. Laustsen, M. T. Hasholt. O.M. Jensen (2015), Void structure of concrete with superabsorbent 617 polymers and its relation to frost resistance of concrete, Mater. Struct., 48, 357-368.

618 [21] M. Tsuji, A. Okuyama, K. Enoki, S. Suksawang (1998), Development of new concrete admixture 619 preventing from leakage of water through cracks, JCA Proc. of Cement \& Concrete, 52, 418-423

620 [22] M. Tsuji, K. Shitama, D. Isobe (1999), Basic studies on simplified curing technique and prevention of 621 initial cracking and leakage of water through cracks of concrete by applying superabsorbent polymers as a new concrete admixture, Journal of the Society of Materials Science, Japan, 48, 1308-1315

[23] H.X.D. Lee, H.S. Wong, N.R. Buenfeld (2010), The potential of superabsorbent polymer for selfsealing cracks in concrete, Adv Appl Ceram, 5, 296-302.

[24] H.X.D. Lee, H.S. Wong, N.R. Buenfeld, (2010), Self-sealing concrete using superabsorbent polymers, International RILEM Conference on Use of Superabsorbent Polymers and other New Additives in Concrete, RILEM Publications SARL, 171-178.

[26] D. Snoeck, K. Van Tittelboom, S. Steuperert, P. Dubruel, N. De Belie (2014), Self-healing

[25] D. Snoeck, S. Steuperaert, K. Van Tittelboom, P. Dubruel, N. De Belie (2012), Visualization of water penetration in cementitious materials with superabsorbent polymers by means of neutron radiography, Cem. Concr. Res., 42, 1113-1121

[28] E. Gartner, F. Tang and S. Weiss, (1985), Saturation factors for calcium hydroxide and calcium sulfates in fresh Portland cement pastes, J. Am. Ceram. Soc., 68, 12, 667-673 
638 [29] C. Y. Rha, J. W. Seong, C. E. Kim, S. K. Lee and W. K. Kim, (1999), Properties and interaction of cement with polymer in the hardened cement pastes added absorbent polymer, J. Mater. Sci., 34, 19, 4653-4659

[30] K. Huber, (1993), Calcium-induced shrinking of polyacrylate chains in aqueous solution, J. Phys. Chem., 97, 38, 9825-9830

[31] R. Schweins, K. Huber (2001), Collapse of sodium polyacrylate chains in calcium salt solutions, Eur. Phys. J. E, 5, 1, 117-126

[32] X.F. Song, J.F. Wei, T. Sh. He (2009), A method to repair concrete leakage through cracks by synthesizing super-absorbent resin in situ, Construction and Building Materials, 23, 386-391

[33] H.X.D. Lee (2011), Self-sealing of cracks in cement-based materials using superabsorbent polymers. $\mathrm{PhD}$ thesis. London, Imperial College London.

[34] C. Schrofl, V. Mechtcherine, M. Gorges (2012), Relation between the molecular structure and the efficiency of superabsorbent polymers (SAP) as concrete admixture to mitigate autogenous shrinkage, Cem. Concr Res., 42, 865-873.

[35] H.X.D. Lee, H.S. Wong, N.R. Buenfeld (2010), Estimating the swelling ratio of superabsorbent polymers in cement-based materials, International RILEM Conference on Use of Superabsorbent Polymers and other New Additives in Concrete, RILEM Publications SARL, 163-170.

[36] W. Khushefati (2004), Healing of cracks in concrete, Department of Civil and Environmental Engineering, Imperial College, University of London, $\mathrm{PhD}$ Thesis

[37] R. Bowen (1986), Groundwater, $2^{\text {nd }}$ Edition, Elsevier Applied Science Publishers Ltd. London.

[38] H.S. Wong, N.R. Buenfeld (2006), Patch microstructure in cement-based materials: Fact or artefact? Cem. Concr. Res., 36 [5] 990-997.

[39] K.L. Scrivener, A.K. Crumbie, P. Laugesen (2004), The interfacial transition zone (ITZ) between cement paste and aggregate in concrete, Interface Science, 12, 411-421. 
662 [40] H.S. Wong, N.R. Buenfeld (2006), Euclidean Distance Mapping for computing microstructural 663 gradients at interfaces in composite materials, Cem. Concr. Res. 36, 1091-1097.

664 [41] H.S. Wong, A.M. Pappas, R.W. Zimmerman, N.R. Buenfeld (2011), Effect of entrained air voids on 665 the microstructure and mass transport properties of concrete, Cem. Concr. Res. 41, 1067-1077.

666 [42] E.E. Underwood (1970), Quantitative Stereology, Addision-Wesley, Reading, Massachusetts.

667 [43] J.C. Russ, R.T. Dehoff (2001), Practical Stereology, Second Edition, New York, Plenum Press.

668 [44] H-W. Reinhardt, M. Joss (2003), Permeability and self-healing of cracked concrete as a function of 669 temperature and crack width, Cem. Concr. Res., 33, 981-985.

670 [45] H.X.D. Lee, H.S. Wong, N.R. Buenfeld (2015), Effect of alkalinity and calcium content on the $671 \quad$ swelling of superabsorbent polymers in cement paste, In preparation.

672 [47] R.D. Toledo Filho, E.F. Silva, A.N.M. Lopes, V. Mechtcherine, and L. Dudziak (2012), Effect of 673 superabsorbent polymers on the workability of concrete and mortar, In: Application of superabsorbent 674 polymers (SAP) in concrete construction, V. Mechtcherine \& H.W. Reinhardt (Editors), State-of-the675 art report, Springer.

676 [48] J. Justs, M. Wyrzykowski, D. Bajare P. Lura (2015), Internal curing by superabsorbent polymers in 677 ultra-high performance concrete, Cem. Concr. Res., 76, 82-90.

678 [49] K. Kovler (2012), Effect of superabsorbent polymers on the mechanical properties of concrete, In: 679 Application of superabsorbent polymers (SAP) in concrete construction, V. Mechtcherine \& H.W. 680 Reinhardt (Editors), State-of-the-art report, Springer.

681 [50] M.T. Hasholt, M.H.S. Jespersen, O.M. Jensen (2010), Mechanical properties of concrete with SAP 682 Part 1: Development of compressive strength, International RILEM Conference on Use of 683 Superabsorbent Polymers and other New Additives in Concrete, RILEM Publications SARL, 117-126. 
Table 1 Oxide composition of Portland cements used

\begin{tabular}{lcccccccccccc}
\hline & \multicolumn{10}{c}{ Oxide composition (\%) } \\
\cline { 2 - 11 } Cement & $\mathrm{SiO}_{2}$ & $\mathrm{Al}_{2} \mathrm{O}_{3}$ & $\mathrm{Fe}_{2} \mathrm{O}_{3}$ & $\mathrm{CaO}$ & $\mathrm{MgO}$ & $\mathrm{SO}_{3}$ & $\mathrm{~K}_{2} \mathrm{O}$ & $\mathrm{Na}_{2} \mathrm{O}$ & $\mathrm{EqNa}_{2} \mathrm{O}$ & $\mathrm{P}_{2} \mathrm{O}_{5}$ & $\mathrm{Free}^{\mathrm{CaO}}$ \\
\hline CEM I (white) & 24.0 & 3.63 & 0.47 & 69.6 & 0.69 & 2.21 & 0.12 & 0.01 & 0.09 & 0.56 & 2.0 \\
CEM II & 29.1 & 10.2 & 4.1 & 48.5 & 1.1 & 2.9 & 1.22 & 0.37 & 1.17 & 0.26 & - \\
\hline
\end{tabular}

696

Table 2 Particle size distribution, specific gravity and water absorption of the aggregates (quartz 698 sharp sand and Thames Valley gravel) used

\begin{tabular}{|c|c|c|c|c|c|c|c|c|c|c|c|c|}
\hline & \multicolumn{9}{|c|}{ Cumulative percentage passing at sieve size (in mm) } & \multicolumn{2}{|c|}{ Specific gravity } & \multirow{2}{*}{$\begin{array}{c}24-\mathrm{hr} \\
\text { absorption } \\
(\%)\end{array}$} \\
\hline & 14 & 10 & 5 & 2.36 & 1.18 & 0.6 & 0.3 & 0.15 & 0.063 & (oven-dry) & (SSD) & \\
\hline Sand & - & - & 99.2 & 86.2 & 77.0 & 66.7 & 23.8 & 4.19 & 1.87 & 2.73 & 2.75 & 0.6 \\
\hline Gravel & 100 & 91.9 & 9.17 & 1.26 & 0.73 & 0.50 & 0.23 & 0.06 & - & 2.76 & 2.81 & 1.6 \\
\hline
\end{tabular}

$700 \quad$ Table 3 Properties of the SAP used

\begin{tabular}{|c|c|c|c|c|}
\hline SAP & $\begin{array}{cc}\text { Source } & \text { Diameter } \\
(\mu \mathrm{m})\end{array}$ & $\begin{array}{c}\text { Bulk } \\
\text { density }\end{array}$ & Polymer type & Swelling ratio, $g / g$ \\
\hline
\end{tabular}




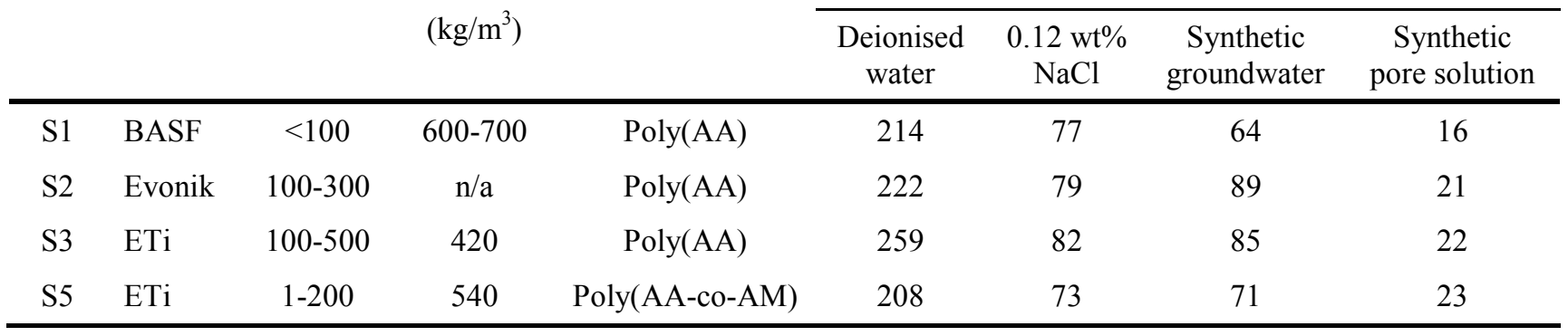

Table 4 Cement paste, mortar and concrete mix proportions

\begin{tabular}{|c|c|c|c|c|c|c|c|c|c|}
\hline \multirow{2}{*}{ Specimen } & \multirow{2}{*}{ ID } & \multirow{2}{*}{$\begin{array}{c}\text { Cement } \\
\text { type }\end{array}$} & \multirow{2}{*}{$\begin{array}{l}\text { Free } \\
w / c\end{array}$} & \multirow{2}{*}{$\begin{array}{l}\text { Total } \\
\mathrm{w} / \mathrm{c}\end{array}$} & \multirow{2}{*}{$\begin{array}{c}\text { Swelling } \\
\text { ratio, } S_{I}\end{array}$} & \multicolumn{4}{|c|}{ Batch quantities $\left(\mathrm{kg} / \mathrm{m}^{3}\right)$} \\
\hline & & & & & & Cement & SAP & Sand & Gravel \\
\hline \multicolumn{10}{|l|}{ Series I: } \\
\hline 1. Cement paste (control) & $\mathrm{CP} 1$ & CEM II & 0.30 & 0.30 & - & 1557 & - & - & - \\
\hline 2. Cement paste $-5 \% \mathrm{~S} 1$ & CP1-5S1 & CEM II & 0.30 & 0.65 & 7 & 978 & 48.9 & - & - \\
\hline 3. Cement paste $-5 \% \mathrm{~S} 2$ & $\mathrm{CP} 1-5 \mathrm{~S} 2$ & CEM II & 0.30 & 0.75 & 9 & 891 & 44.5 & - & - \\
\hline 4. Cement paste $-5 \% \mathrm{~S} 3$ & $\mathrm{CP} 1-5 \mathrm{~S} 3$ & CEM II & 0.30 & 0.75 & 9 & 891 & 44.5 & & \\
\hline 5. Cement paste $-4 \%$ S5 & CP1-4S5 & CEM II & 0.30 & 1.10 & 20 & 682 & 27.3 & - & - \\
\hline \multicolumn{10}{|l|}{ Series II: } \\
\hline 6. Cement paste (control) & $\mathrm{CP} 2$ & CEM I & 0.30 & 0.30 & - & 1590 & - & - & - \\
\hline 7. Cement paste (control)* & $\mathrm{CP} 2 *$ & CEM I & 0.30 & 0.30 & - & 1526 & - & - & - \\
\hline 8. Cement paste $-13 \% \mathrm{~S} 2 *$ & $\mathrm{CP} 2-13 \mathrm{~S} 2 *$ & CEM I & 0.30 & 0.75 & 3.5 & 826 & 112 & - & - \\
\hline 9. Cement paste $-8 \% \mathrm{~S} 5 *$ & $\mathrm{CP} 2-8 \mathrm{~S} 5^{*}$ & CEM I & 0.30 & 0.75 & 5.6 & 853 & 71.1 & - & - \\
\hline \multicolumn{10}{|l|}{ Series III: } \\
\hline 10. Mortar (control) & M & CEM II & 0.50 & 0.50 & - & 593 & - & 1365 & - \\
\hline 11. Mortar - 5\% S1 & M-5S1 & CEM II & 0.50 & 0.85 & 7 & 409 & 20.5 & 1365 & - \\
\hline 12. Mortar $-5 \% \mathrm{~S} 2$ & $\mathrm{M}-5 \mathrm{~S} 2$ & CEM II & 0.50 & 1.10 & 12 & 340 & 17.0 & 1365 & - \\
\hline
\end{tabular}

Series IV: 


\begin{tabular}{|c|c|c|c|c|c|c|c|c|c|}
\hline 13. Concrete (control) * & $\mathrm{C}^{*}$ & CEM I & 0.40 & 0.40 & - & 461 & - & 630 & 1160 \\
\hline 14. Concrete - $13 \% \mathrm{~S} 2 *$ & $\mathrm{C}-13 \mathrm{~S} 2 *$ & CEM I & 0.40 & 1.11 & 5.3 & 225 & 30.4 & 630 & 1160 \\
\hline 15. Concrete $-8 \% \mathrm{~S} 5 *$ & $\mathrm{C}-8 \mathrm{~S} 5 *$ & CEM I & 0.40 & 1.12 & 8.6 & 224 & 18.7 & 630 & 1160 \\
\hline
\end{tabular}

Notes: * Mixes marked with asterisk contain 4\% calcium nitrate by weight of cement.

Table 5 Effect of high SAP dosages on 28-day compressive strength

\begin{tabular}{|c|c|c|c|c|c|}
\hline Specimen & ID & $\mathrm{w} / \mathrm{c}$ & $\begin{array}{l}\text { Average strength } \\
\qquad\left(\mathrm{N} / \mathrm{mm}^{2}\right)\end{array}$ & $\begin{array}{l}\text { Total strength } \\
\text { decrease }(\%)\end{array}$ & $\begin{array}{l}\text { Strength decrease } \\
\text { per } 1 \% \text { SAP }(\%)\end{array}$ \\
\hline Cement paste (control) & $\mathrm{CP} 1$ & 0.3 & $77.6(1.7)$ & - & - \\
\hline Cement paste $-5 \% \mathrm{~S} 2$ & $\mathrm{CP} 1-5 \mathrm{~S} 2$ & 0.3 & $10.0(0.3)$ & 87.1 & 17.4 \\
\hline Cement paste (control)* & $\mathrm{CP} 2 *$ & 0.3 & $86.9(1.3)$ & - & - \\
\hline Cement paste $-13 \% \mathrm{~S} 2 *$ & $\mathrm{CP} 2-13 \mathrm{~S} 2 *$ & 0.3 & $10.9(0.1)$ & 87.4 & 6.7 \\
\hline Mortar (control) & M & 0.5 & $40.3(1.8)$ & - & - \\
\hline Mortar - 5\% S2 & M-5S2 & 0.5 & $8.1(0.2)$ & 79.9 & 16.0 \\
\hline Concrete (control)* & $C^{*}$ & 0.4 & $74.7(1.2)$ & - & - \\
\hline Concrete $-13 \% \mathrm{~S} 2 *$ & $\mathrm{C}-13 \mathrm{~S} 2 *$ & 0.4 & $10.6(0.3)$ & 85.8 & 6.6 \\
\hline
\end{tabular}

712 Notes: Standard deviation shown in parentheses. Mixes marked with asterisk contain 4\% calcium nitrate by

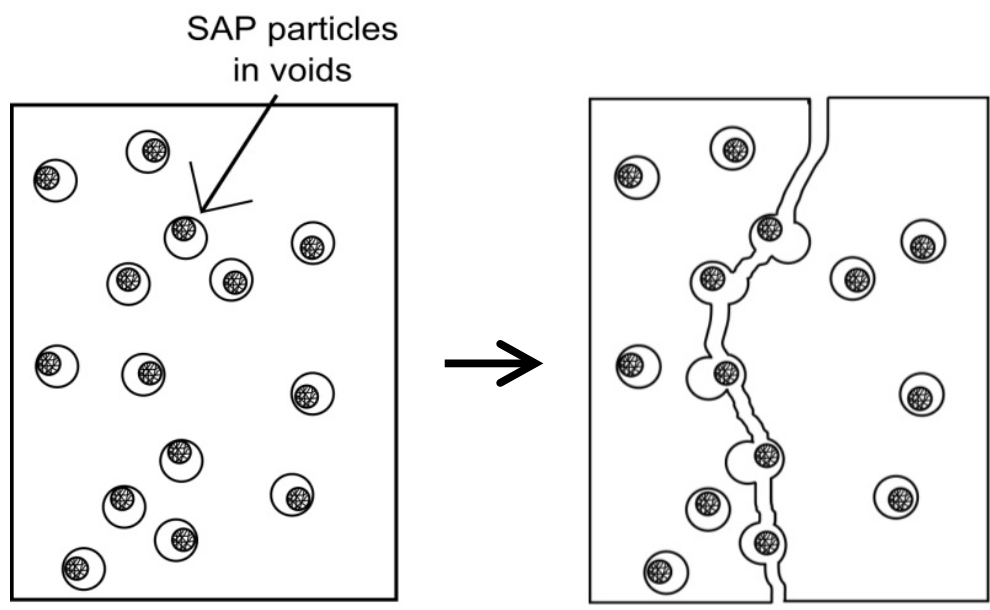

(a) SAP is added to concrete during batching. Initial swelling $\left(S_{l}\right)$ is confined. As concrete hardens, the SAP shrinks and lies dormant in the microstructure.

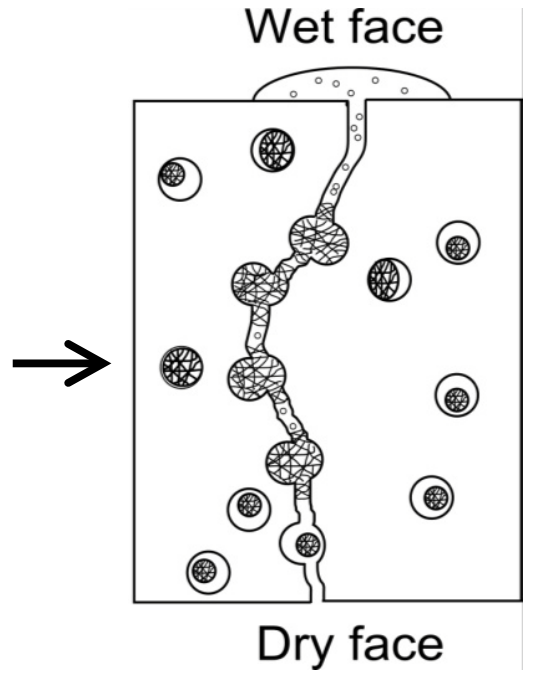

(b) Subsequent cracking propagates through SAP voids, exposing the polymer. (c) Ingress of water causes SAP to swell $\left(S_{2}\right)$, expanding into the crack and restricting further flow. 


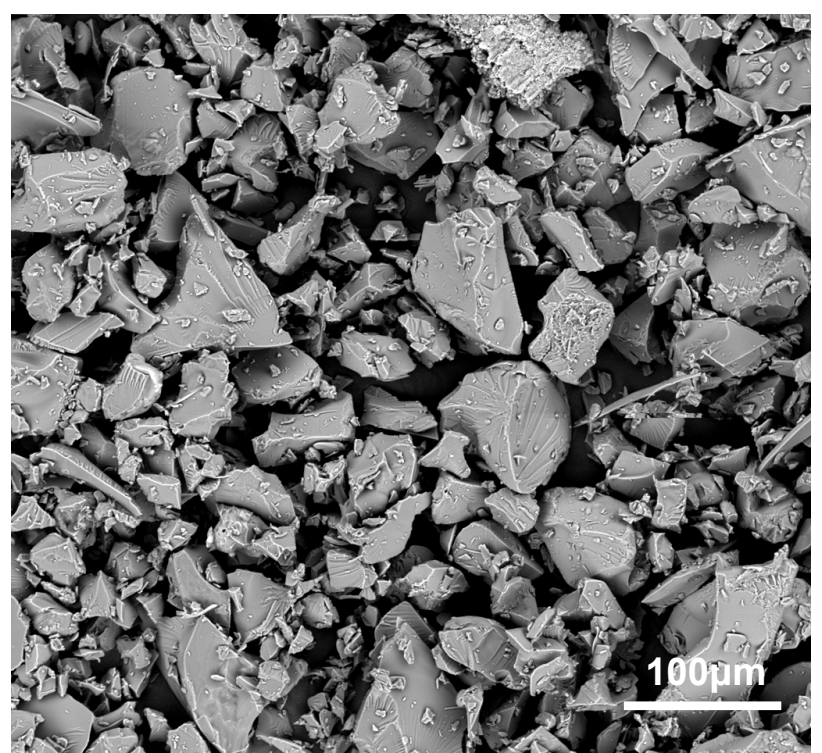

(a) $\mathrm{S} 1$

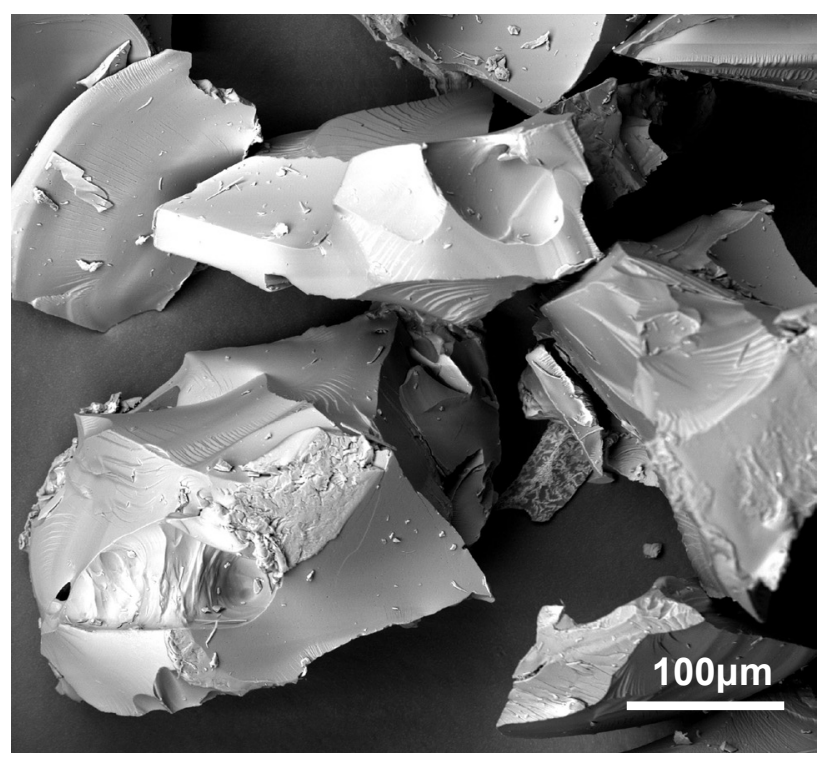

(b) S2 


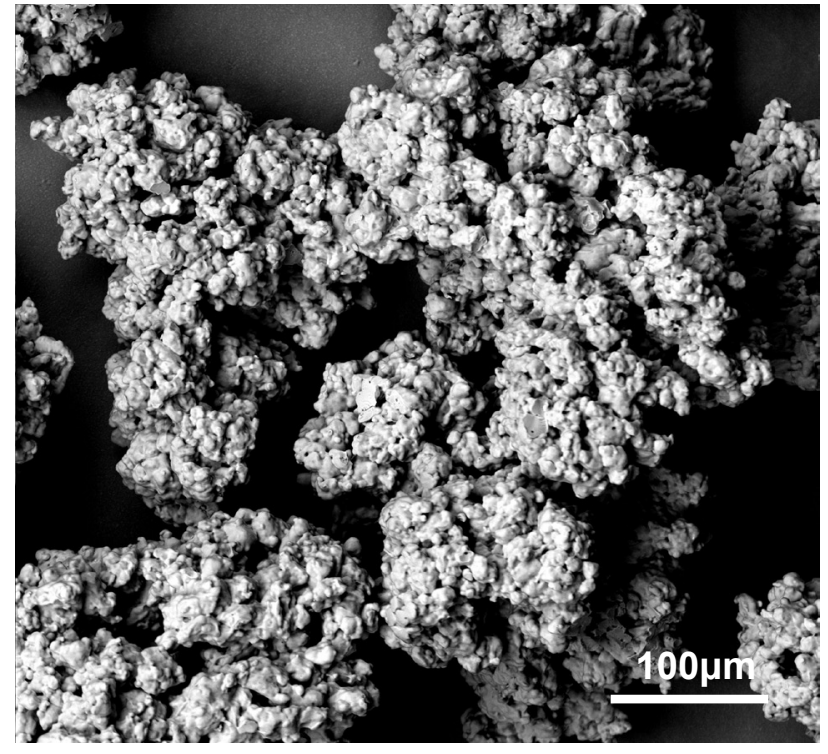

(c) S3

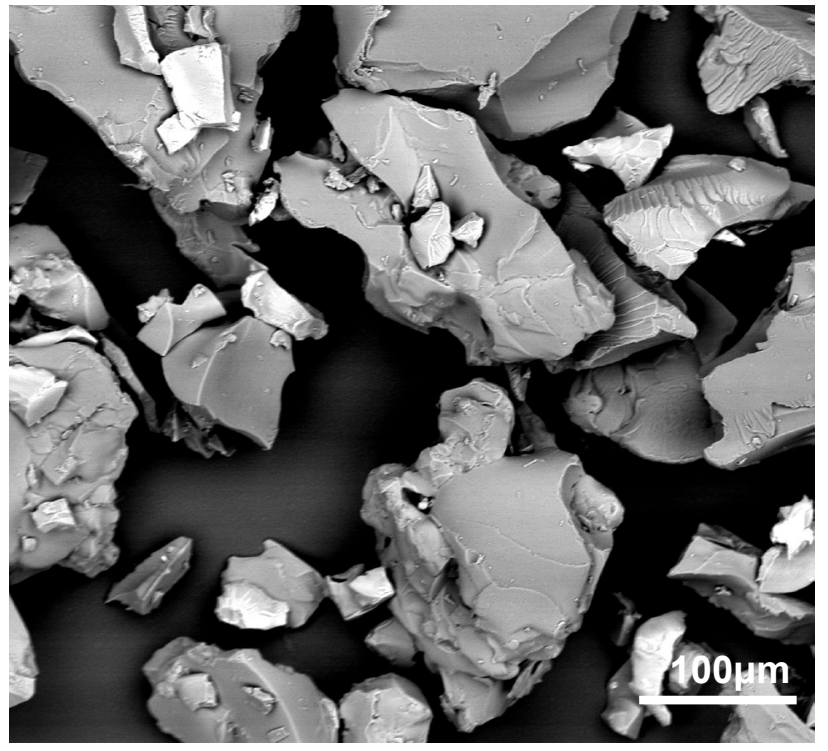

(d) S5

Fig 2 Scanning electron micrographs show that S1, S2 and S5 consist of smooth angular particles while $\mathrm{S3}$ particles are rough textured with an agglomerate structure. $\mathrm{S1}$ has the smallest particle size.

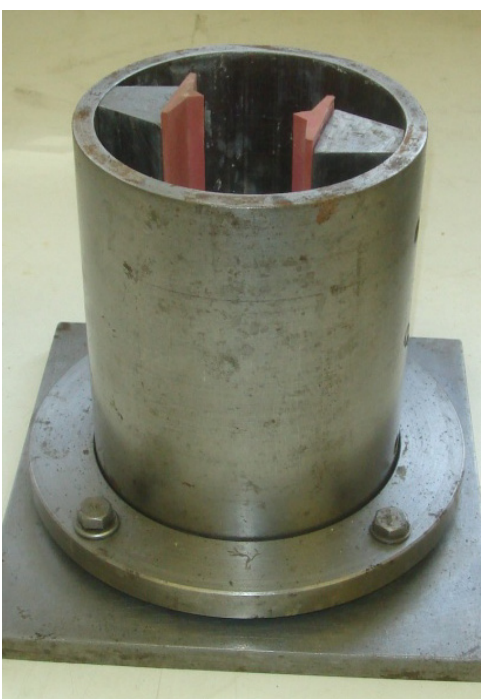

(a)

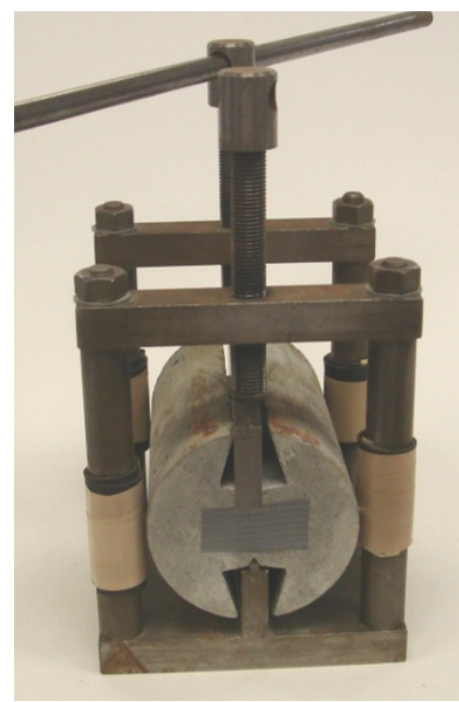

(b)

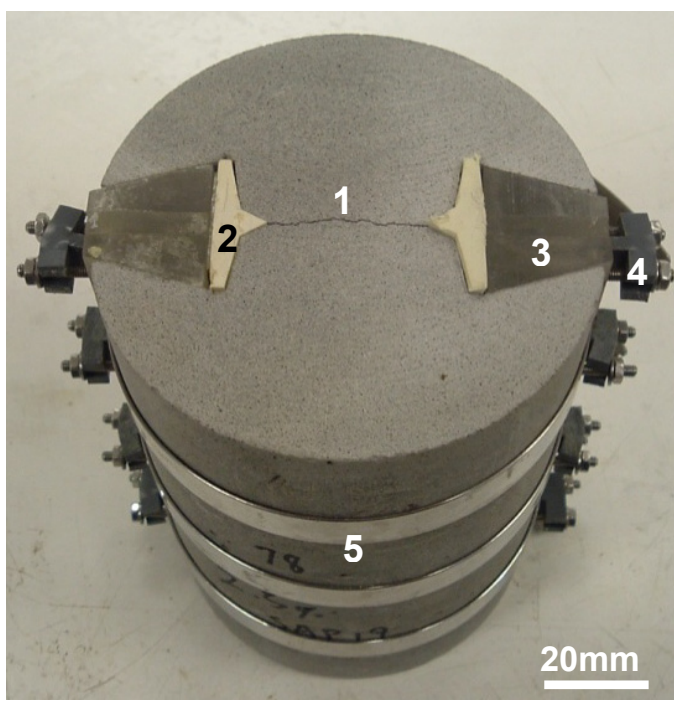

(c)
740

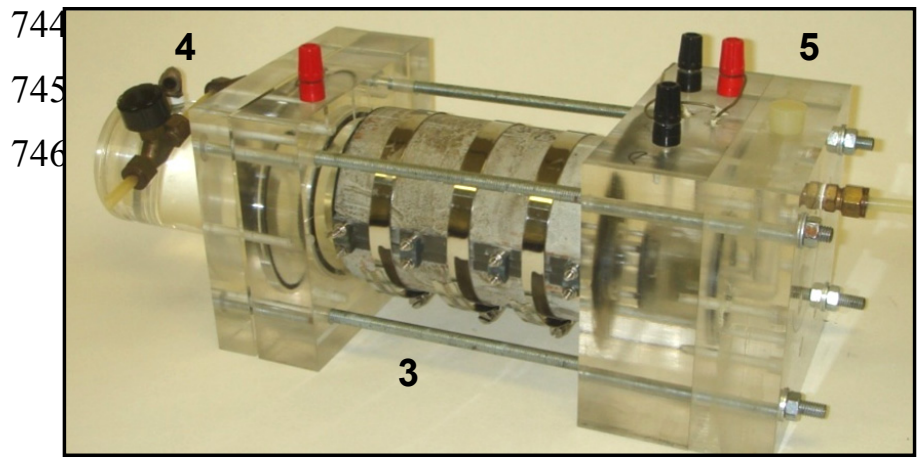




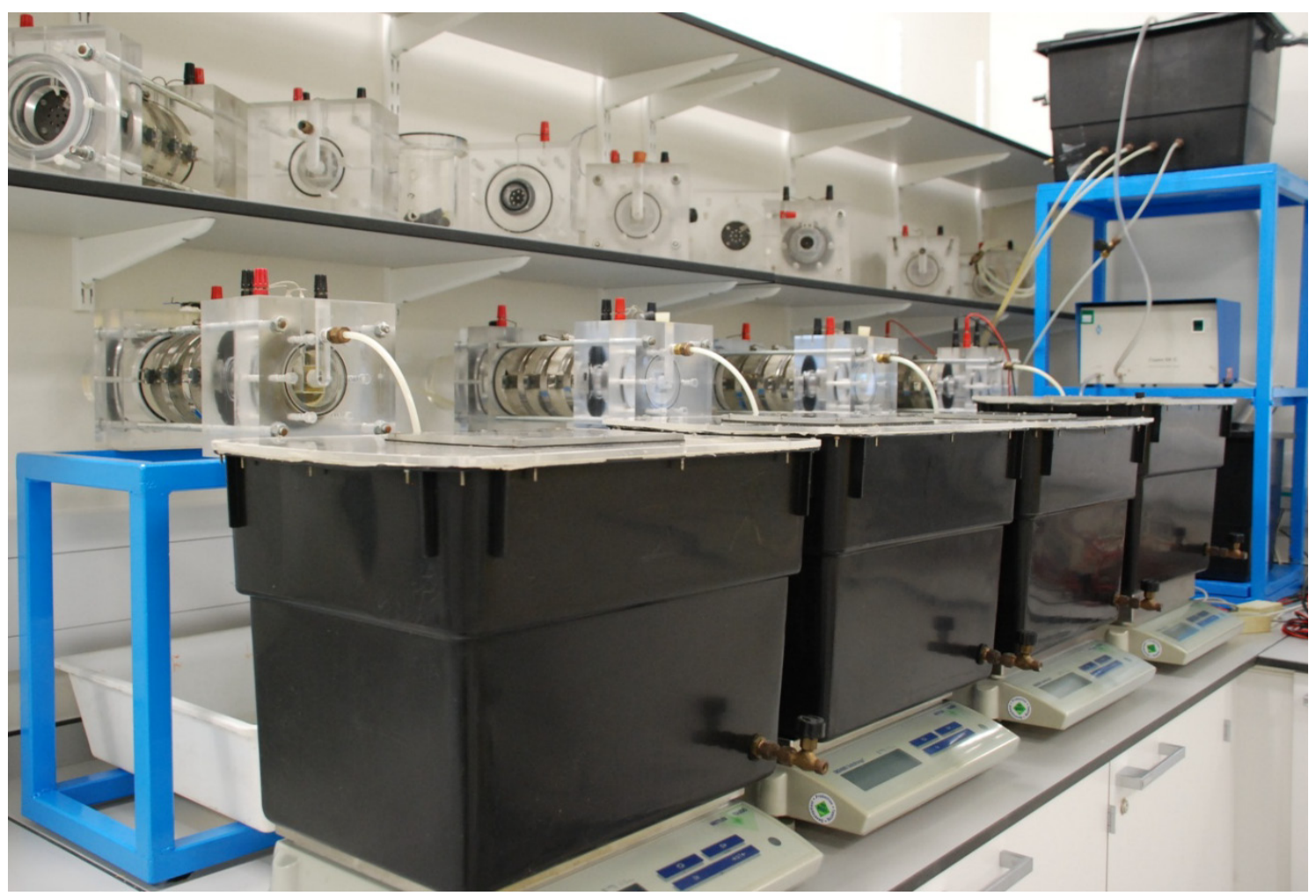

Fig. 4 Setup for the flow through crack (FTC) experiment which consists of the upper tank filled with 0.02M NaCl solution (1), pump (2), assembled specimen (3), inlet (4) and outlet (5) cells, lower tank (6) and electronic balance (7) connected to data loggers (not shown).

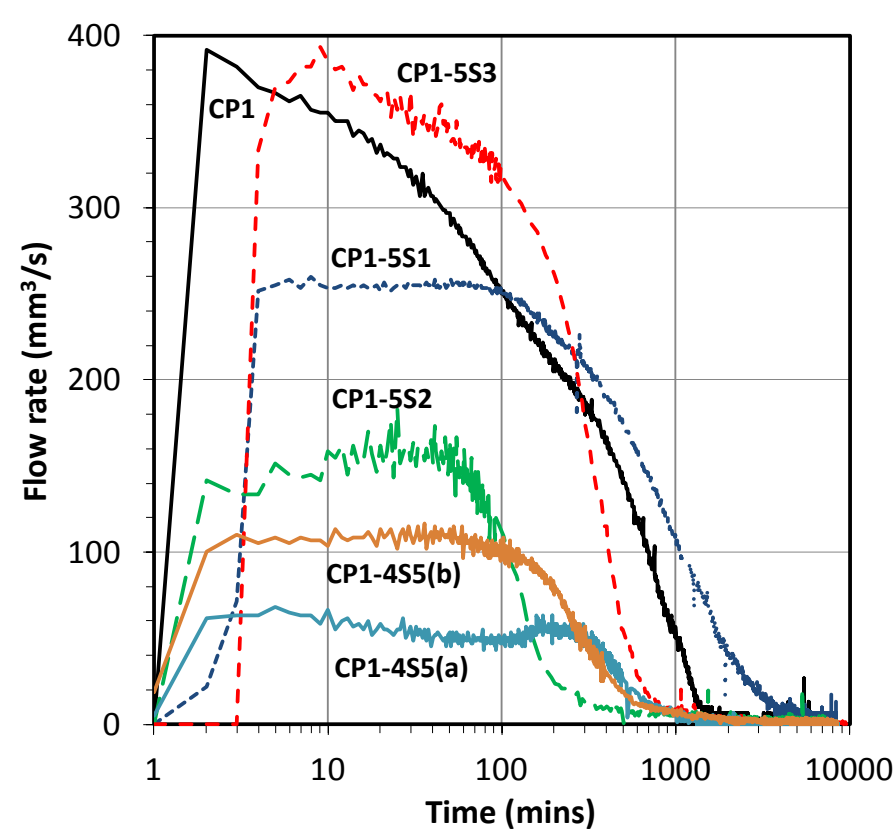

(a)

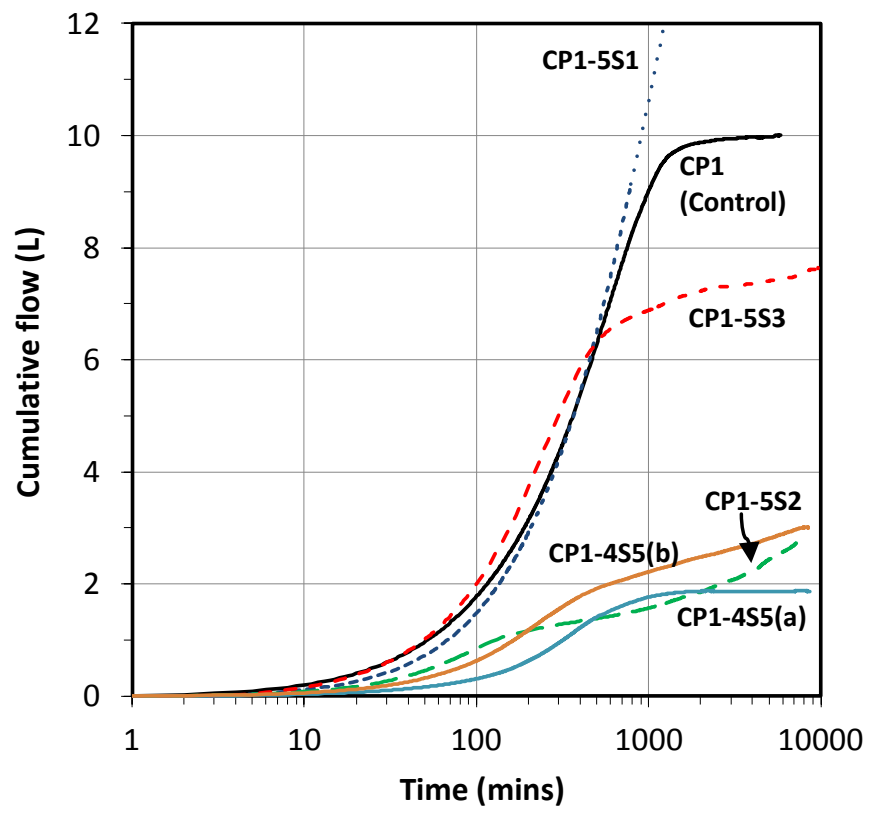

(b)

Fig. 5 Flow rate (a) and cumulative flow (b) of $\mathrm{NaCl}$ through a $0.2 \mathrm{~mm}$ crack for pastes from Series I (w/c 0.3). 


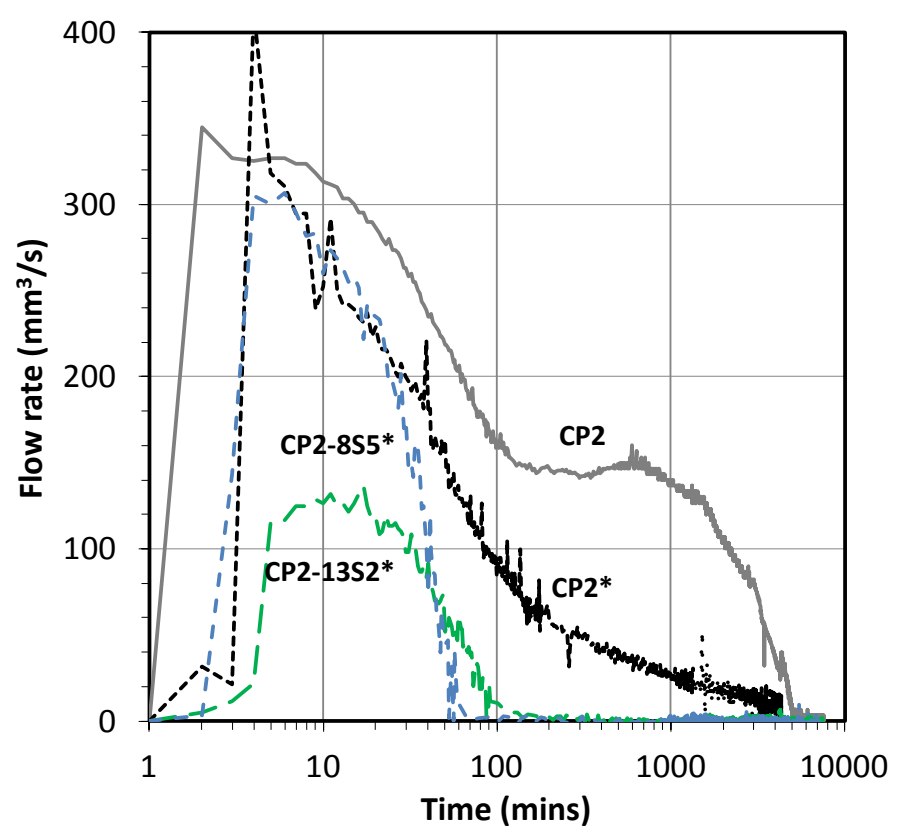

(a)

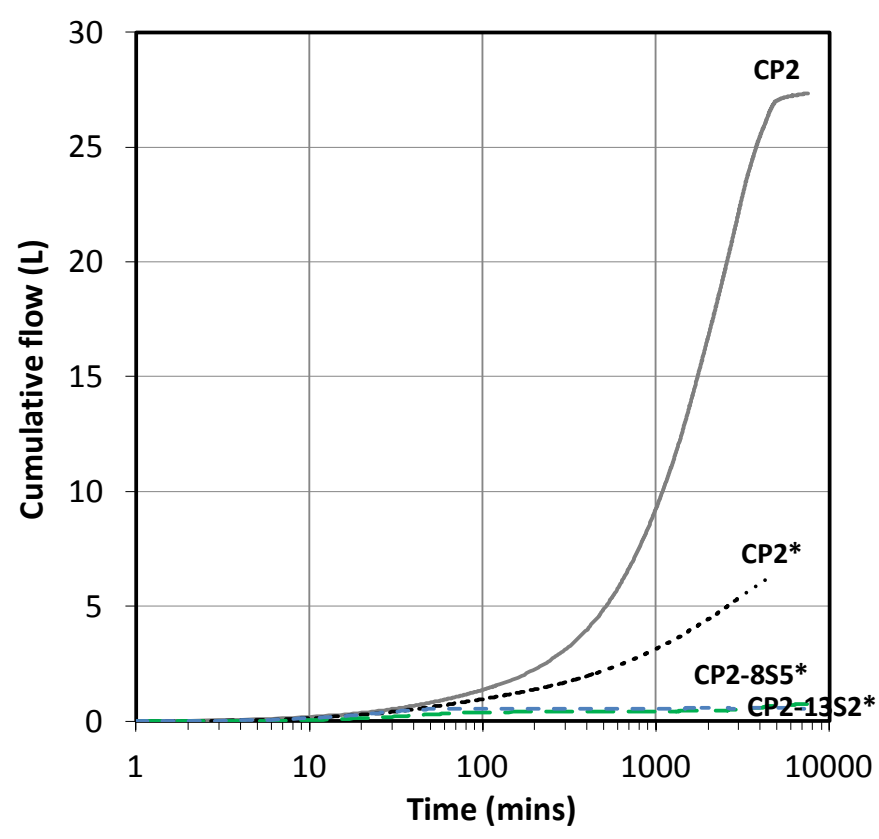

(b)

Fig. 6 Flow rate (a) and cumulative flow (b) of $\mathrm{NaCl}$ through a $0.2 \mathrm{~mm}$ crack for pastes from Series II 756

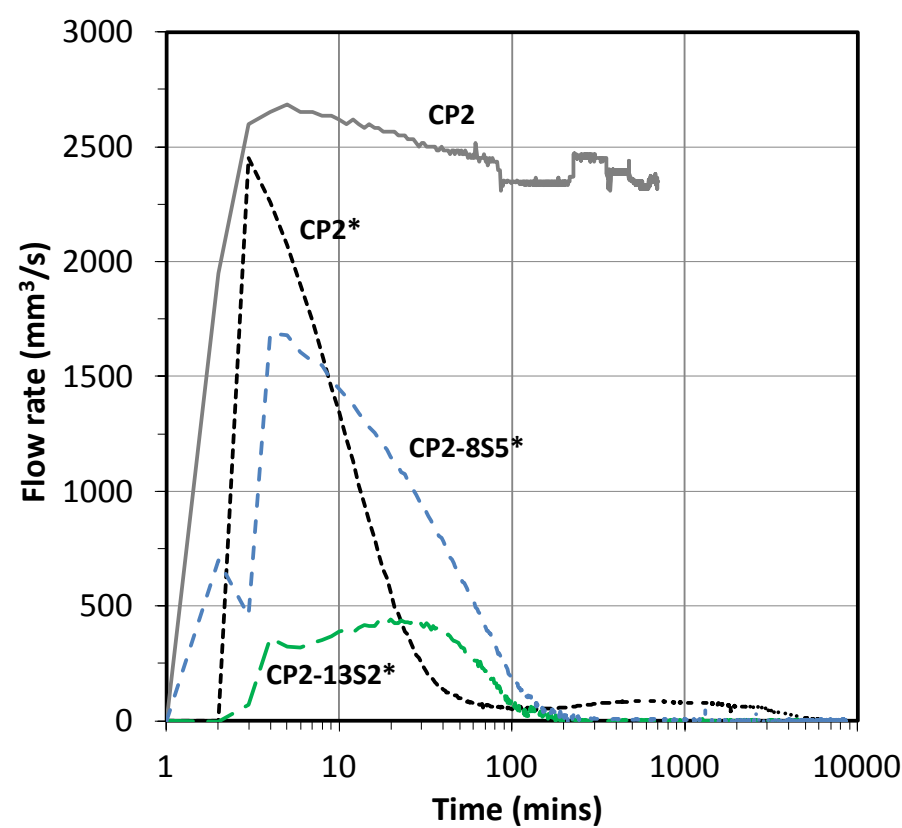

(a)

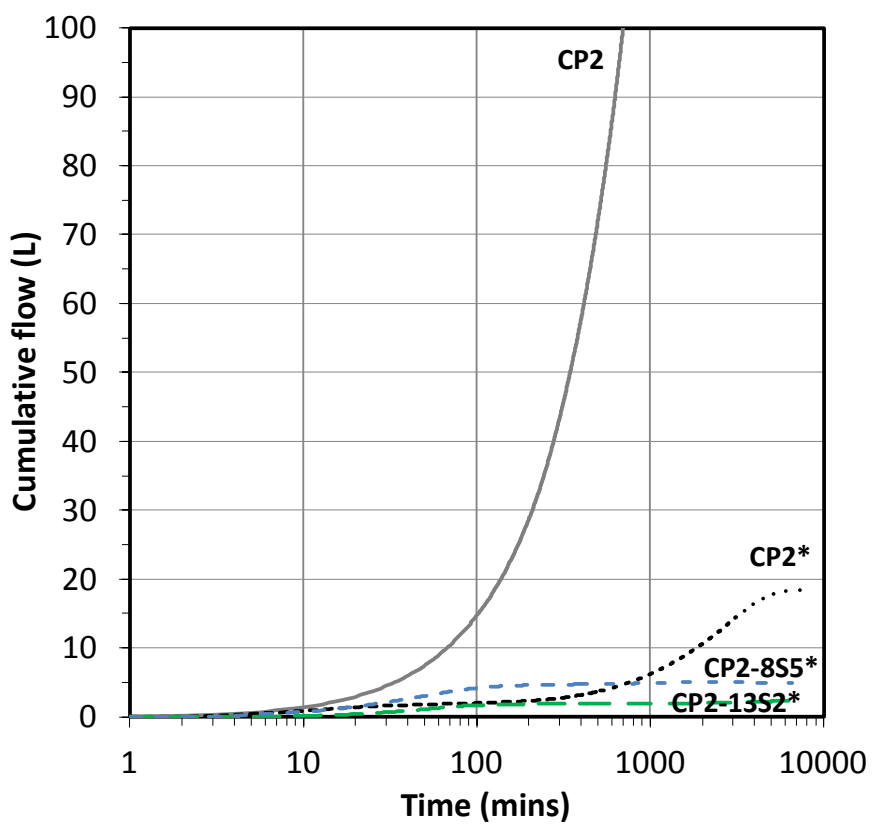

(b) 


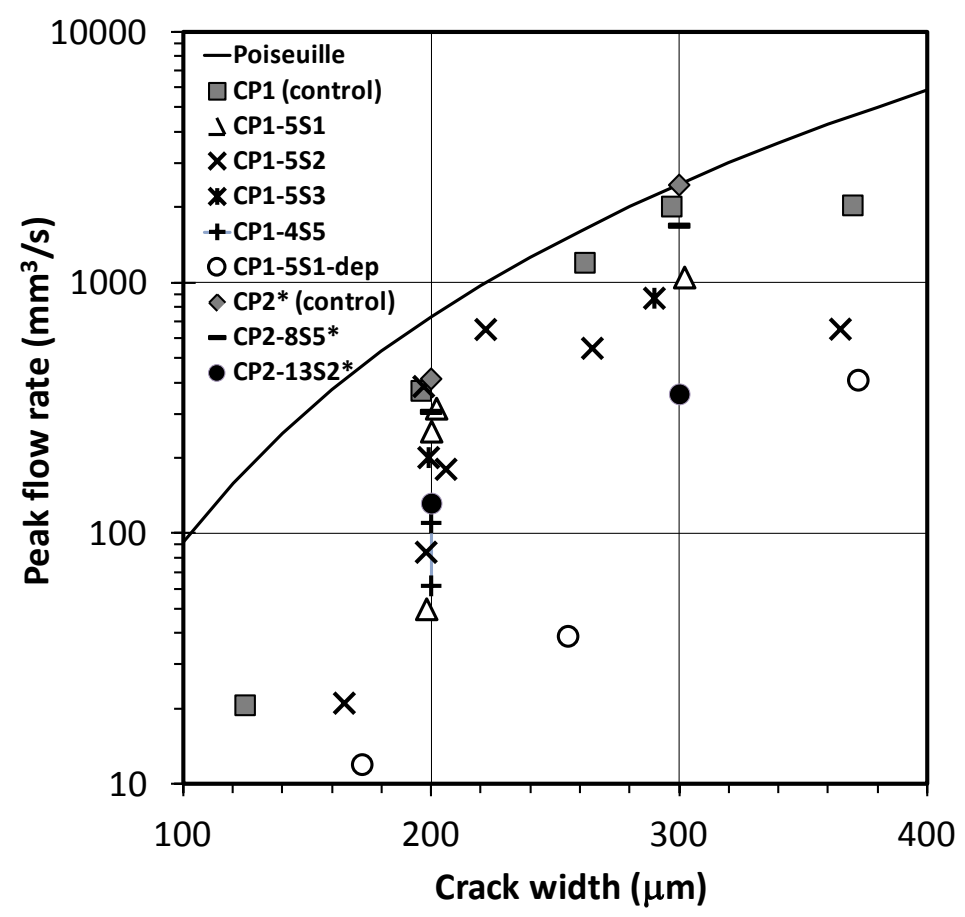

Fig. 8 Influence of crack width on the peak flow rate for pastes from Series I \& II (w/c 0.3).

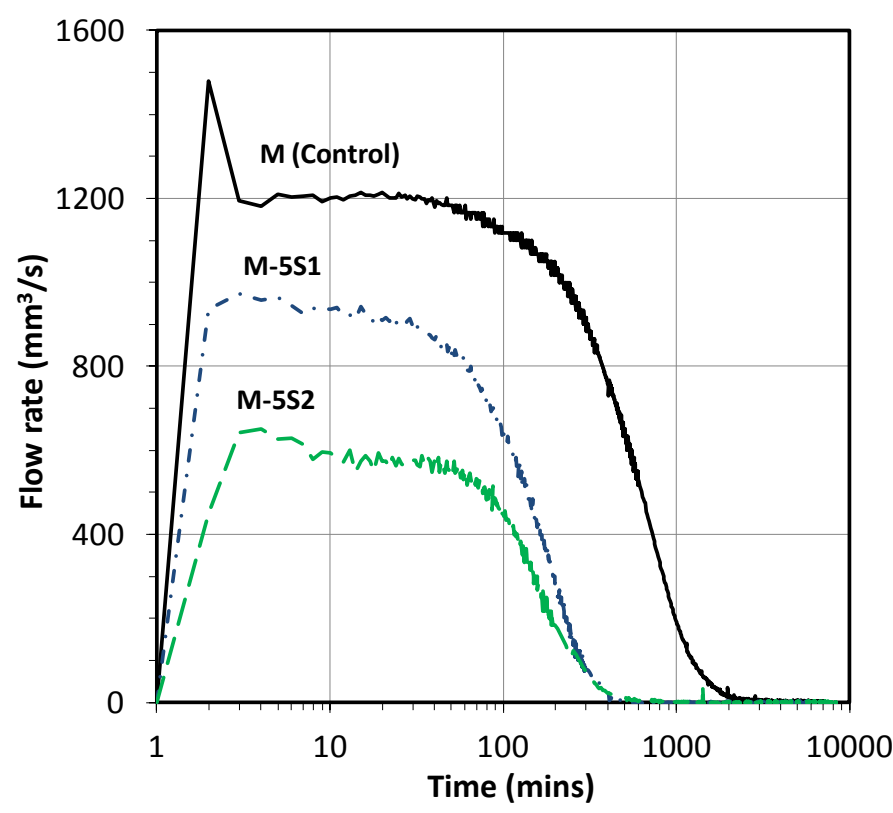

(a)

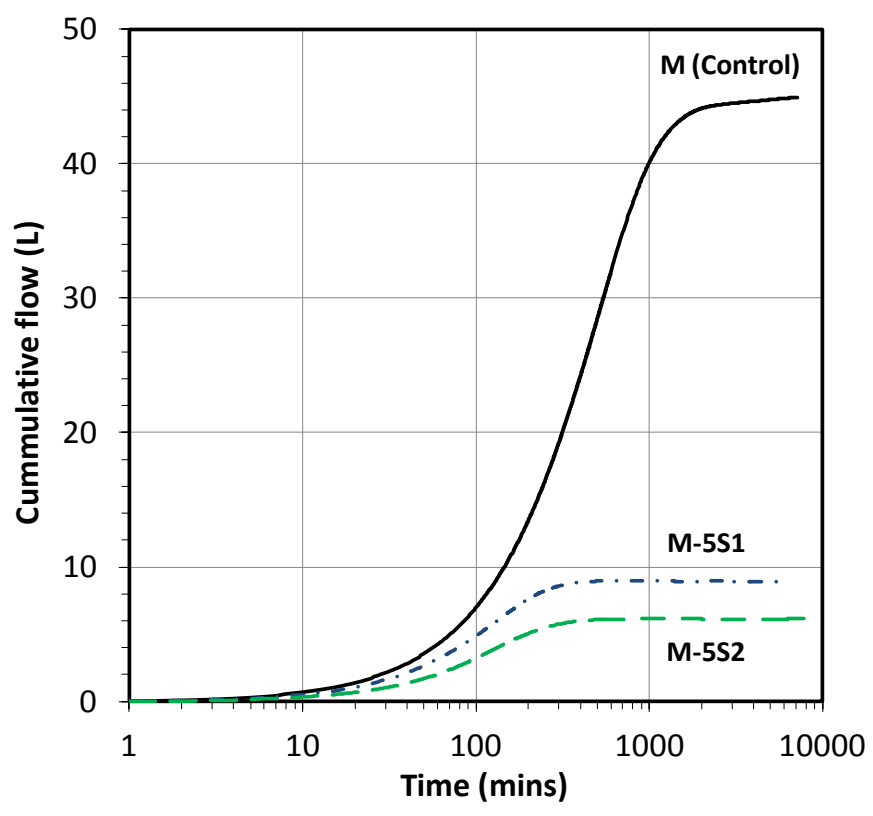

(b)

Fig. 9 Flow rate (a) and cumulative flow (b) of $\mathrm{NaCl}$ through a $0.3 \mathrm{~mm}$ crack for mortars from Series III (w/c 0.5). 


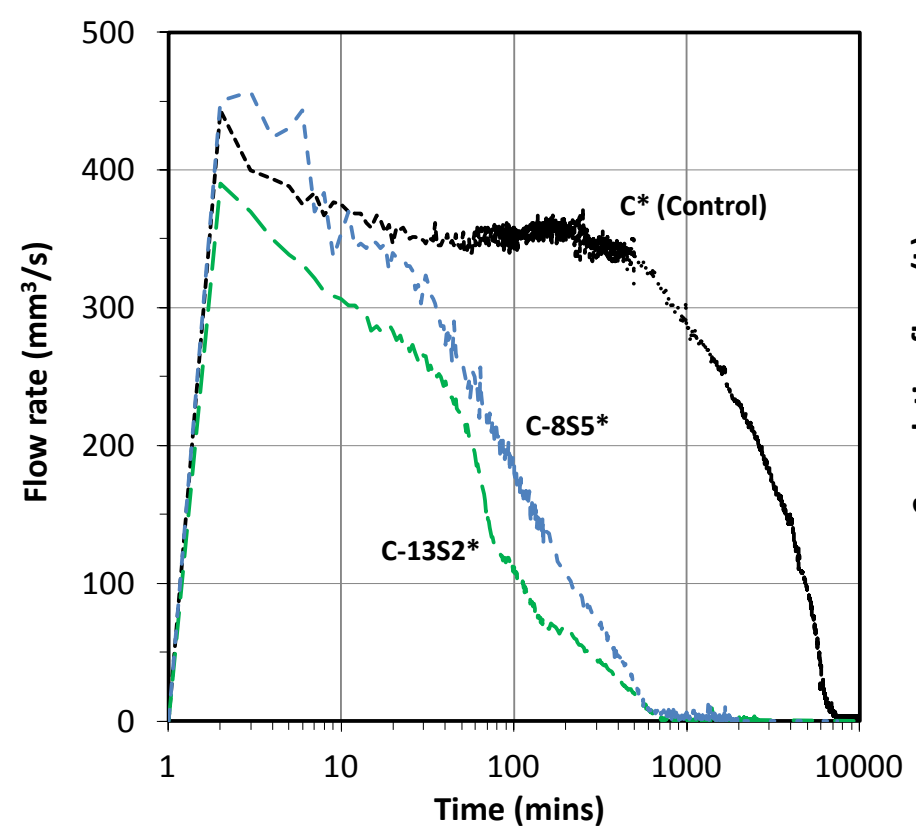

(a)

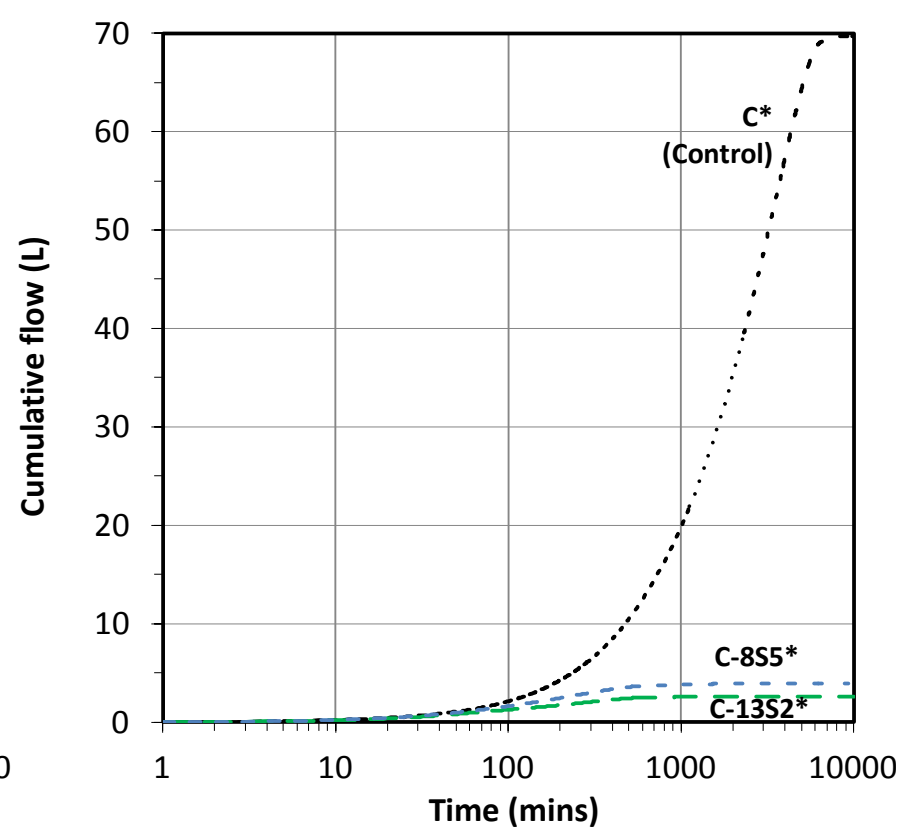

(b)
766 767 768

Fig. 10 Flow rate (a) and cumulative flow (b) of $\mathrm{NaCl}$ through a $0.3 \mathrm{~mm}$ crack for concretes from Series IV (w/c 0.4).

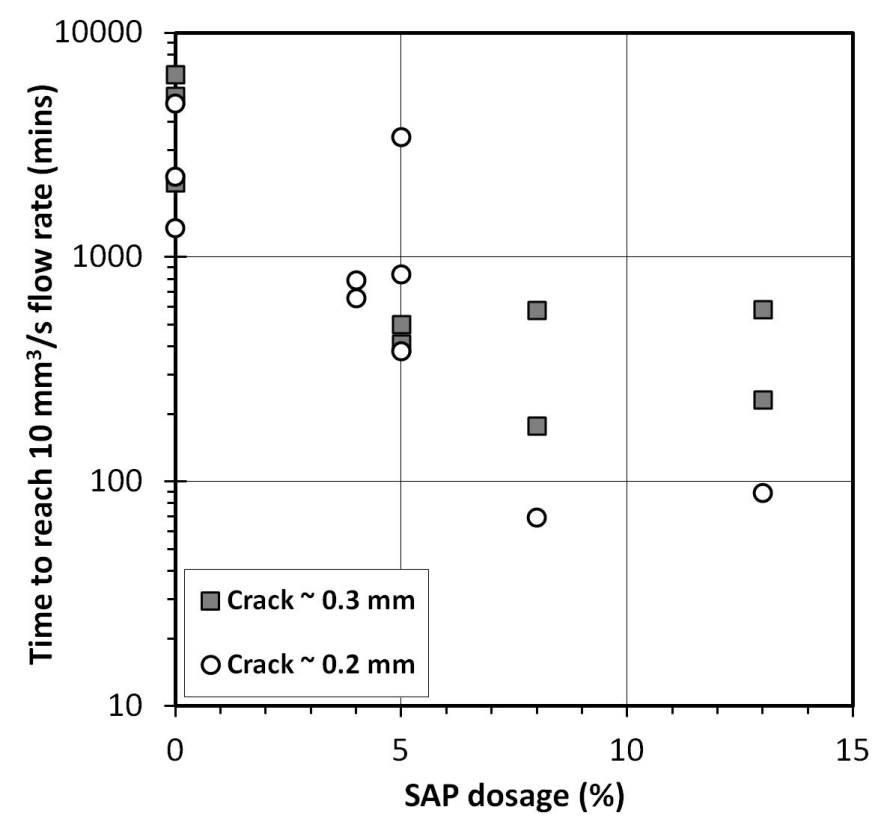

(a)

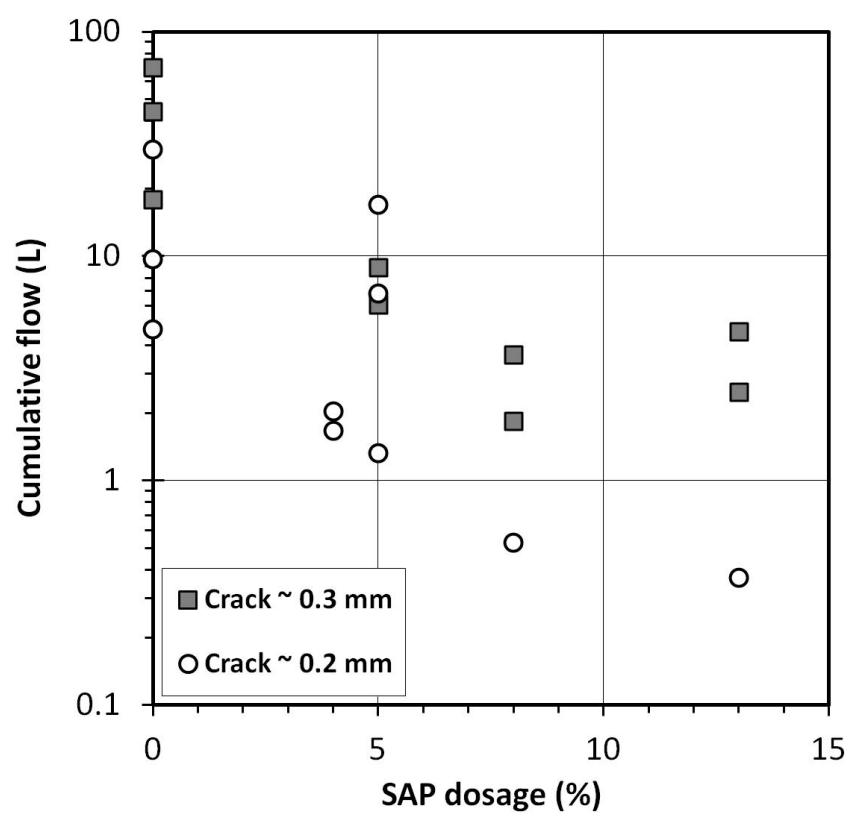

(b)

Fig. 11 Effect of SAP dosage (\% wt. of cement) on a) the time to reach negligible flow rate $\left(=10 \mathrm{~mm}^{3} / \mathrm{s}\right)$ and b) cumulative flow for all specimens. 


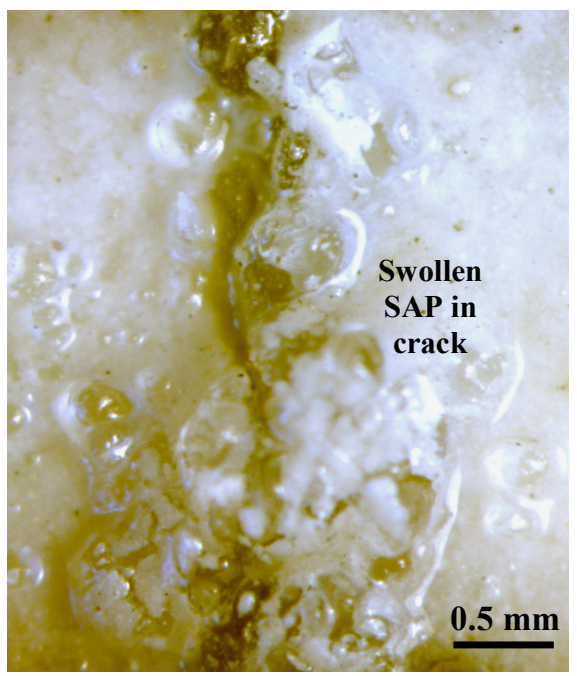

a) Upstream face, imaged immediately after FTC experiment showing the swollen SAP in crack.

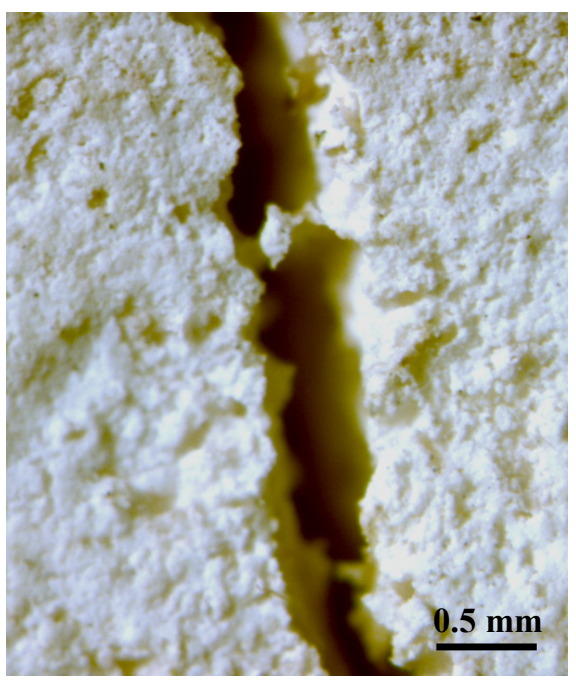

b) Upstream face, imaged after FTC experiment and drying at room temperature for 24 hours

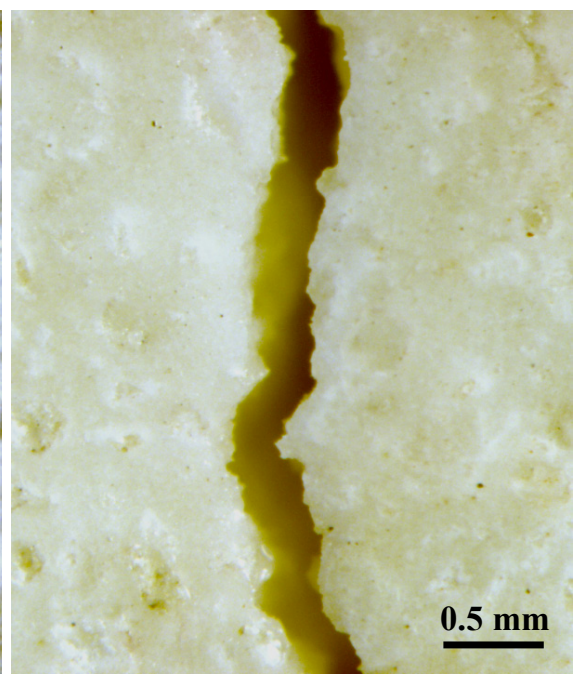

c) Downstream face, imaged immediately after FTC experiment

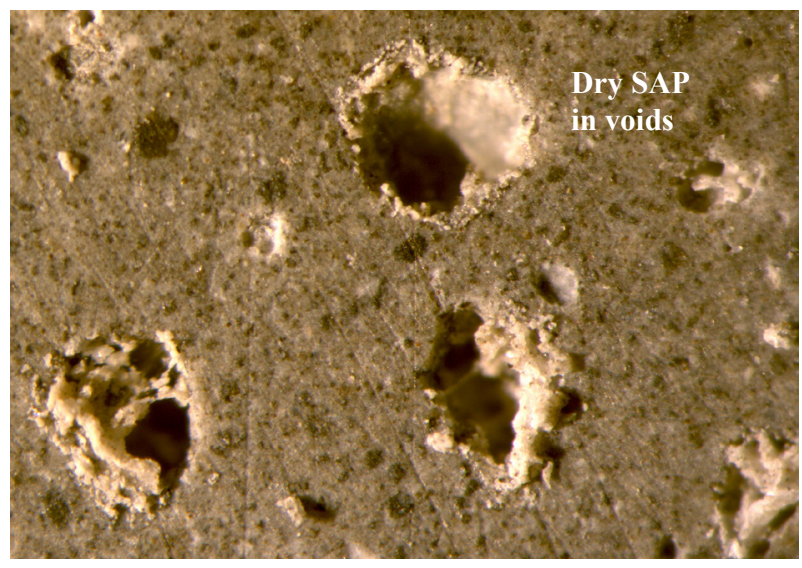

d) Before wetting

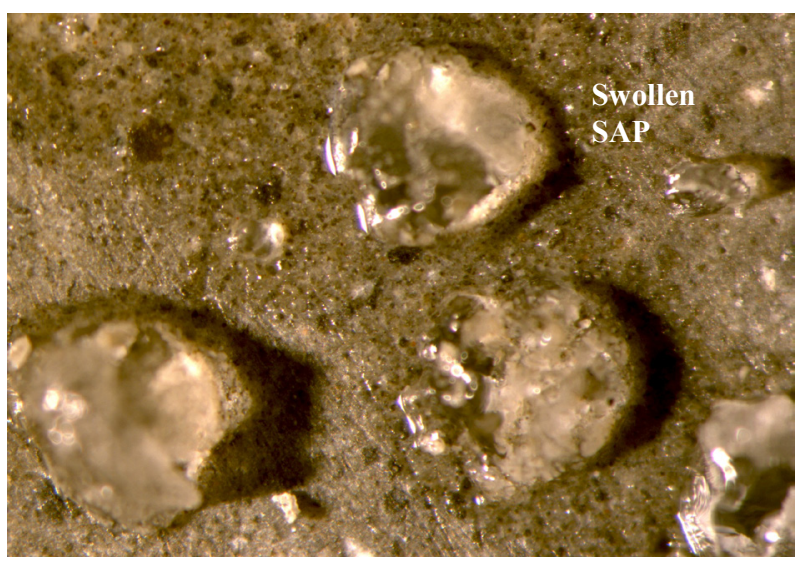

e) After wetting

779 Fig. 12 Stereo micrographs of a sealed crack after the FTC experiment, specimen is CP2-8S5*. Figures 780 (d) and (e) show close-up area matching stereo micrographs of crack surface before and after wetting. 


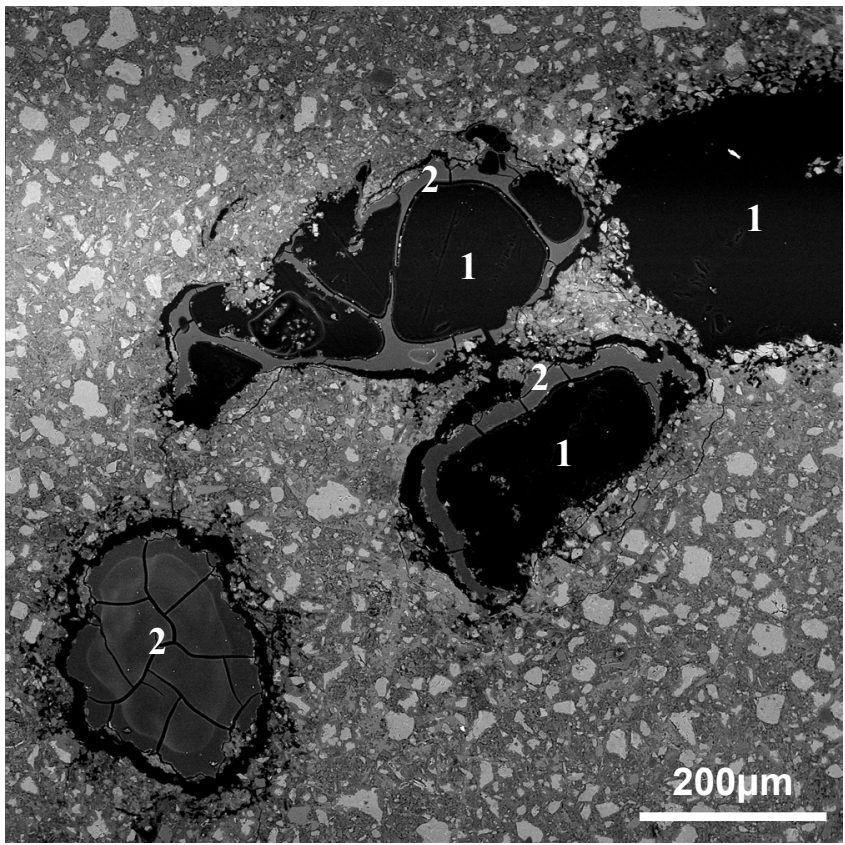

(a) $\mathrm{CP} 1-5 \mathrm{~S} 2$

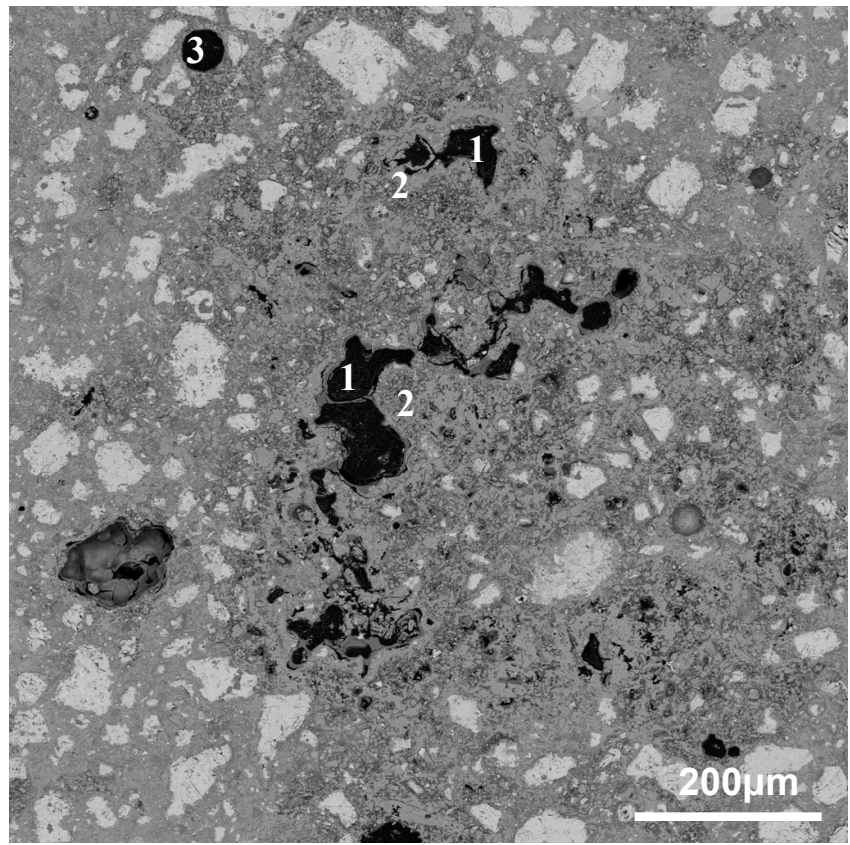

(b) $\mathrm{CP} 1-5 \mathrm{~S} 3$ 


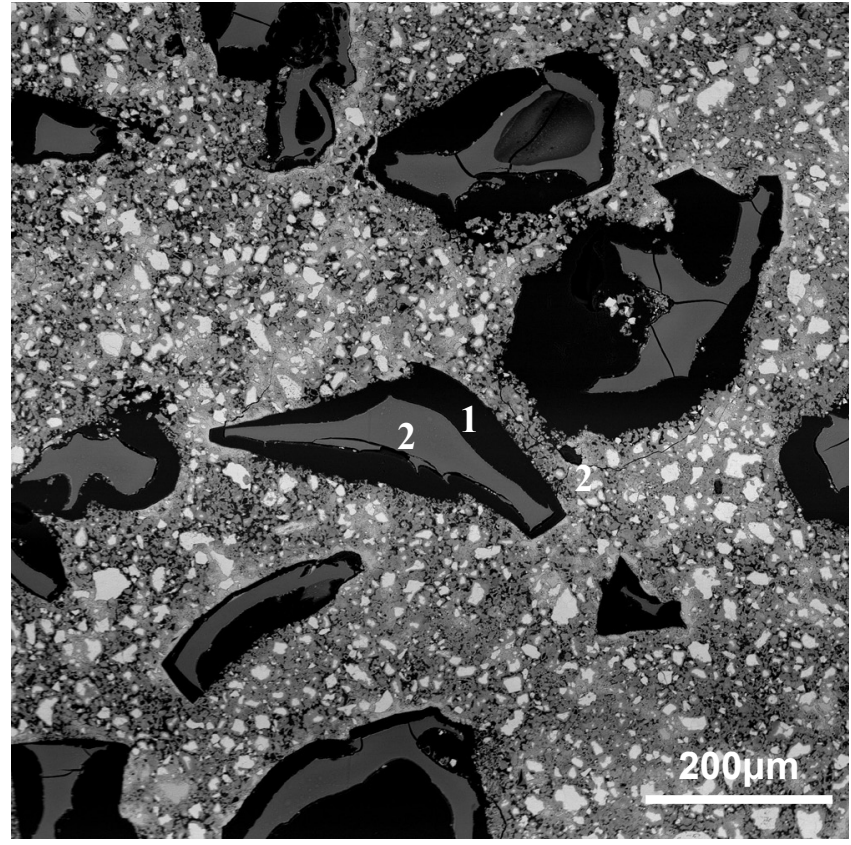

(c) $\mathrm{CP} 2-13 \mathrm{~S} 2 *$

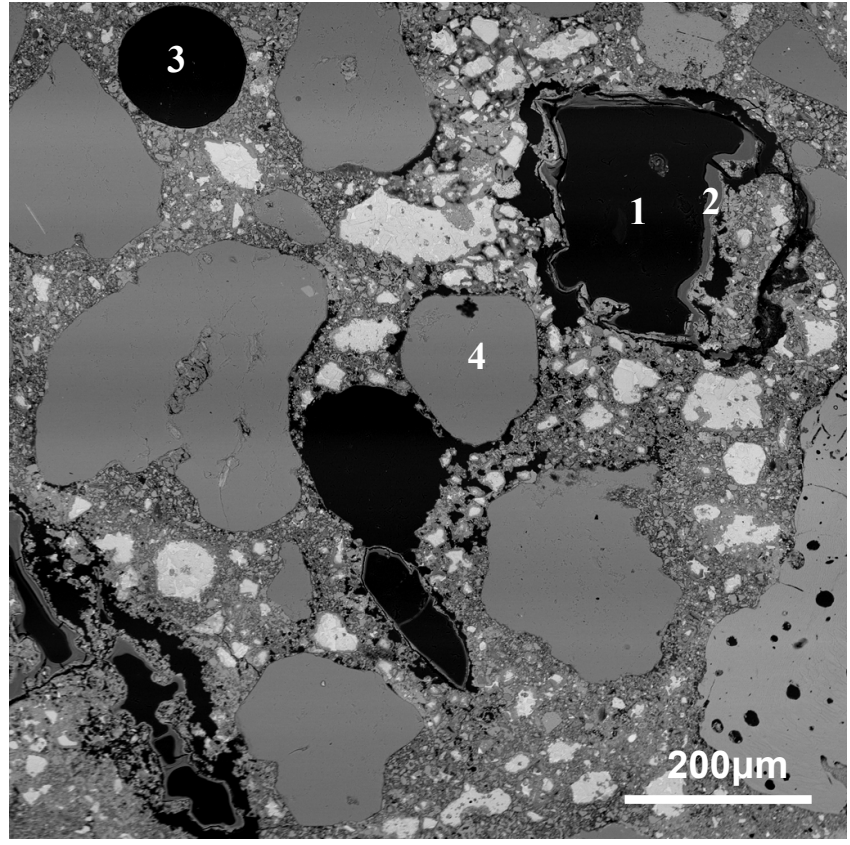

(d) $\mathrm{M}-5 \mathrm{~S} 2$
788

789

790

791

792

793

\section{2}

Fig. 13 Selection of images from BSE microscopy showing the effect of SAP on microstructure of cement-based materials. The micrographs highlight the SAP voids (1), remnants of the collapsed SAP

\author{
(2), entrapped air (3), aggregate particles (4) and the SAP/cement paste interface.
}




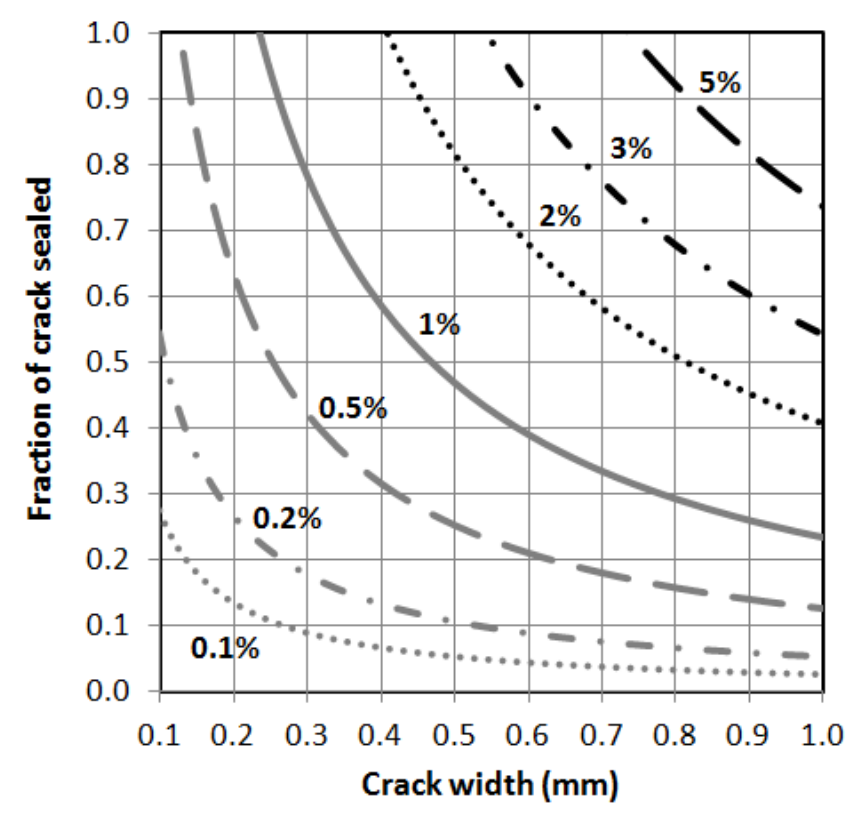

(a) $S_{1}=10 \mathrm{~g} / \mathrm{g}, S_{2}=75 \mathrm{~g} / \mathrm{g}, d_{o}=100 \mu \mathrm{m}$

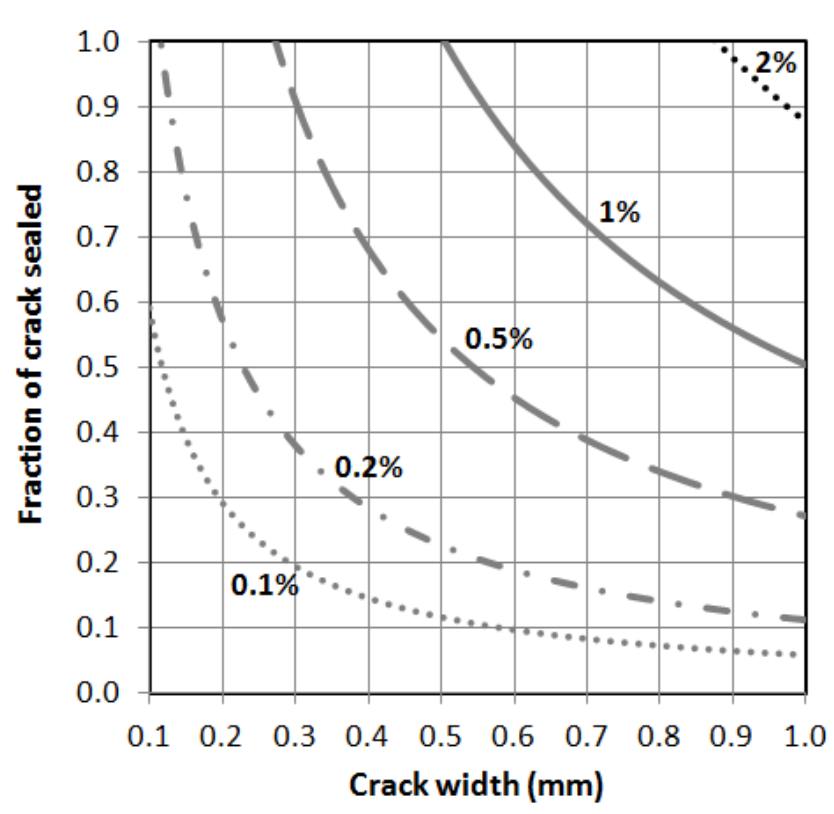

c) $S_{I}=10 \mathrm{~g} / \mathrm{g}, \underline{S}_{2}=150 \mathrm{~g} / \mathrm{g}, d_{o}=100 \mu \mathrm{m}$

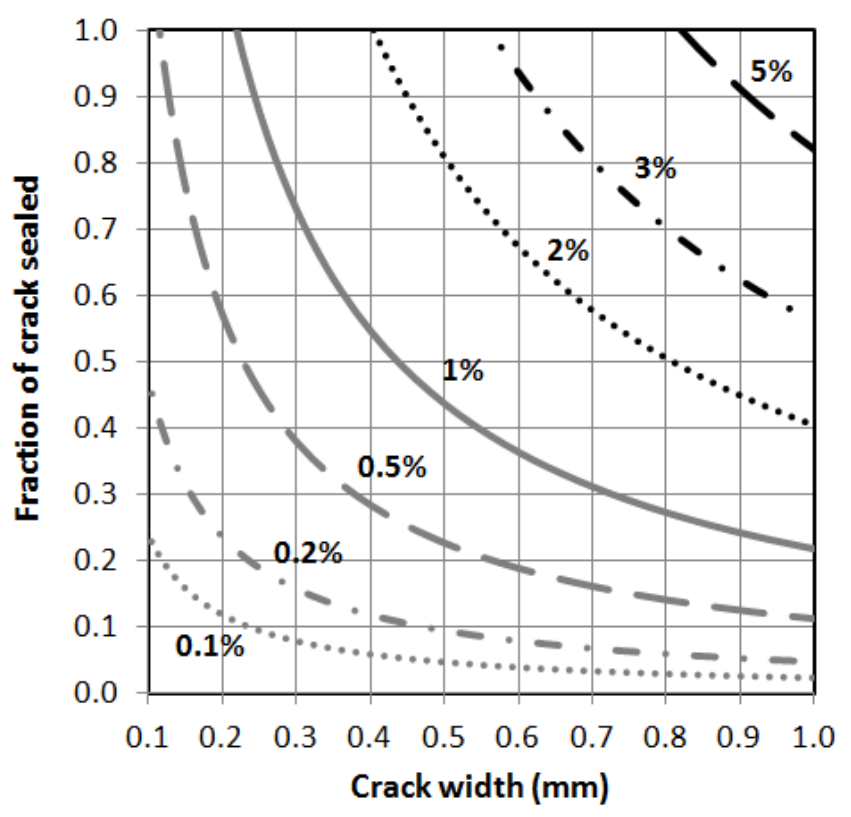

(b) $\underline{S}_{1}=5 \mathrm{~g} / \mathrm{g}, S_{2}=75 \mathrm{~g} / \mathrm{g}, d_{o}=100 \mu \mathrm{m}$

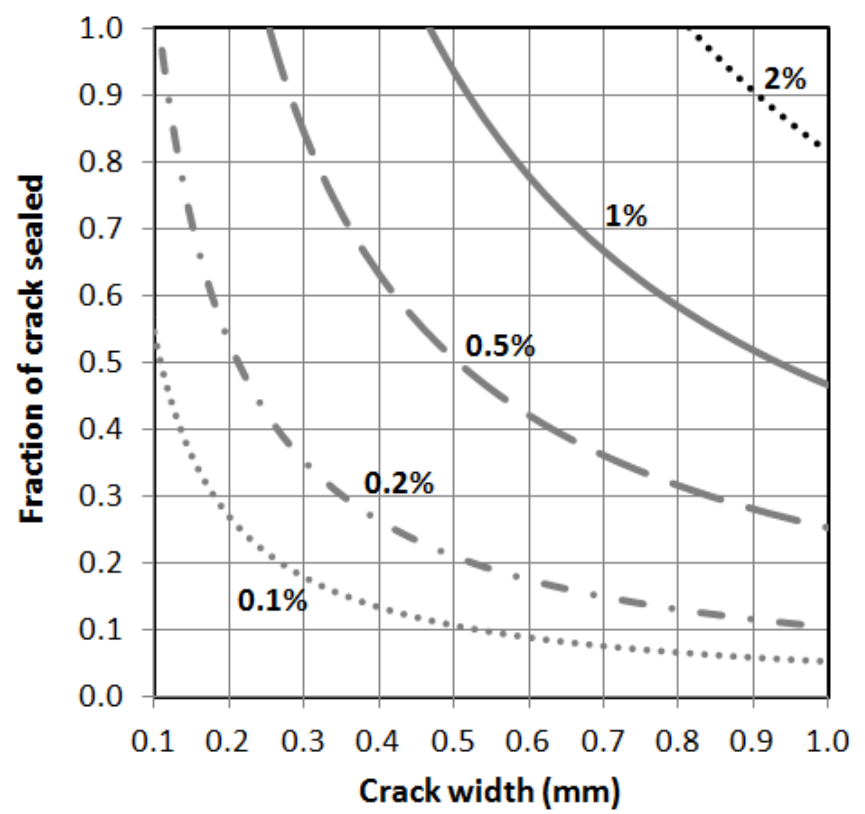

d) $S_{1}=10 \mathrm{~g} / \mathrm{g}, S_{2}=75 \mathrm{~g} / \mathrm{g}, \underline{d_{o}}=200 \mu \mathrm{m}$

Fig. 14 Modelling of the crack fraction sealed as a function of crack width and SAP dosage ( $\alpha$, wt $\%$ of cement) for a cement paste at $0.3 \mathrm{w} / \mathrm{c}$ ratio. Results show that crack sealing can be enhanced by depressing the initial swelling ratio $S_{1}$ (Fig. b), increasing the subsequent swelling ratio $S_{2}$ in crack (Fig. c) and increasing the particle size of SAP, $d_{o}$ (Fig. d). 
Cement \& Concrete Research (2016), 79, 194-208

801 